\title{
NGNP Reactor Coolant Chemistry Control Study
}

\author{
Brian Castle
}

The INL is a

U.S. Department of Energy National Laboratory

operated by

Battelle Energy Alliance

\section{November 2010}
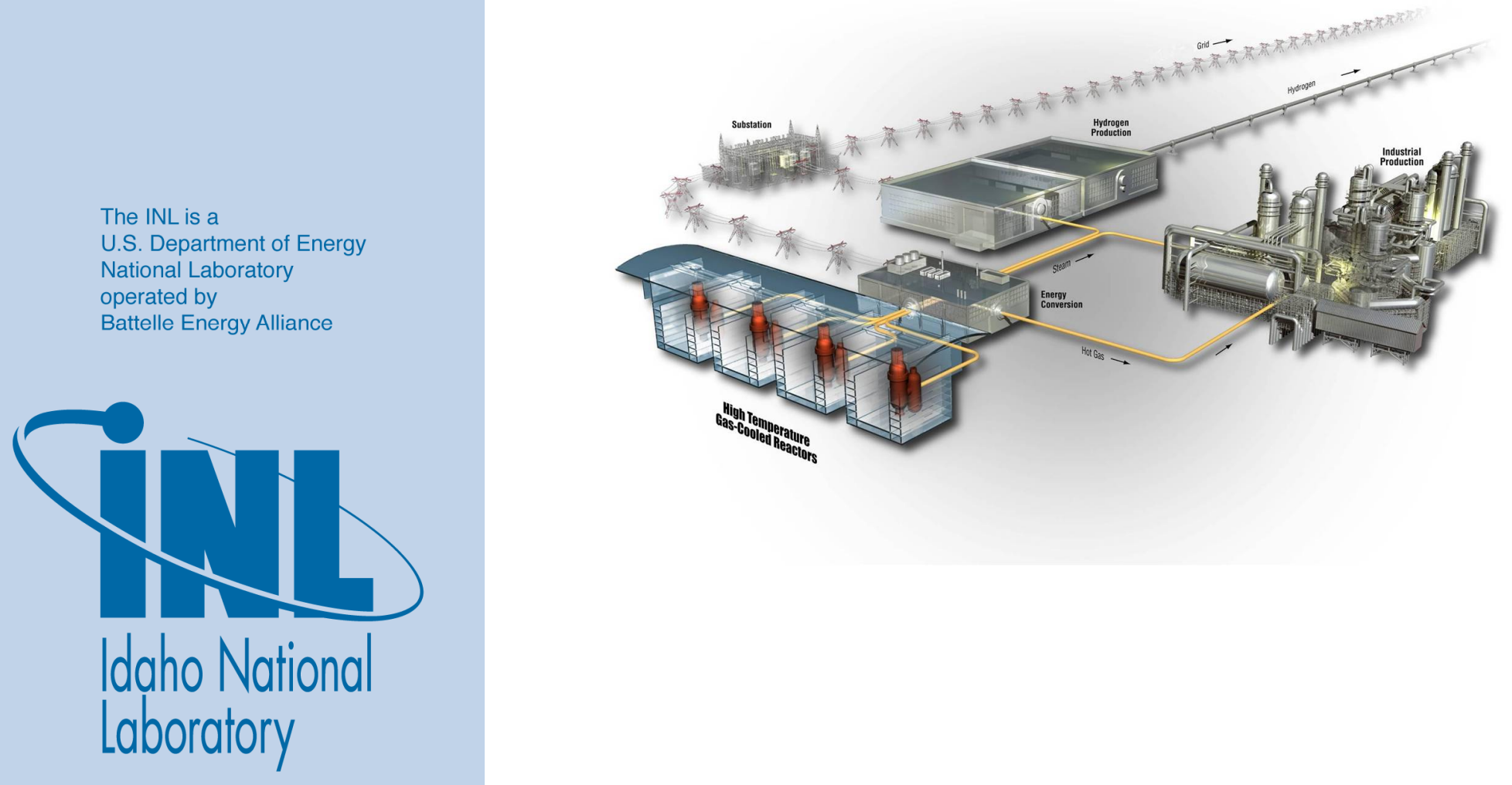


\section{DISCLAIMER}

This information was prepared as an account of work sponsored by an agency of the U.S. Government. Neither the U.S. Government nor any agency thereof, nor any of their employees, makes any warranty, expressed or implied, or assumes any legal liability or responsibility for the accuracy, completeness, or usefulness, of any information, apparatus, product, or process disclosed, or represents that its use would not infringe privately owned rights. References herein to any specific commercial product, process, or service by trade name, trade mark, manufacturer, or otherwise, does not necessarily constitute or imply its endorsement, recommendation, or favoring by the U.S. Government or any agency thereof. The views and opinions of authors expressed herein do not necessarily state or reflect those of the U.S. Government or any agency thereof. 
INL/EXT-10-19533

Revision 1

\title{
NGNP Reactor Coolant Chemistry Control Study
}

\author{
Brian Castle
}

November 2010

Idaho National Laboratory

Next Generation Nuclear Plant Project

Idaho Falls, Idaho 83415

Prepared for the

U.S. Department of Energy

Office of Nuclear Energy

Under DOE Idaho Operations Office

Contract DE-AC07-05ID14517 

Next Generation Nuclear Plant Project

\title{
NGNP Reactor Coolant Chemistry Control Study
}

\author{
INL/EXT-10-19533 \\ Revision 1
}

November 2010
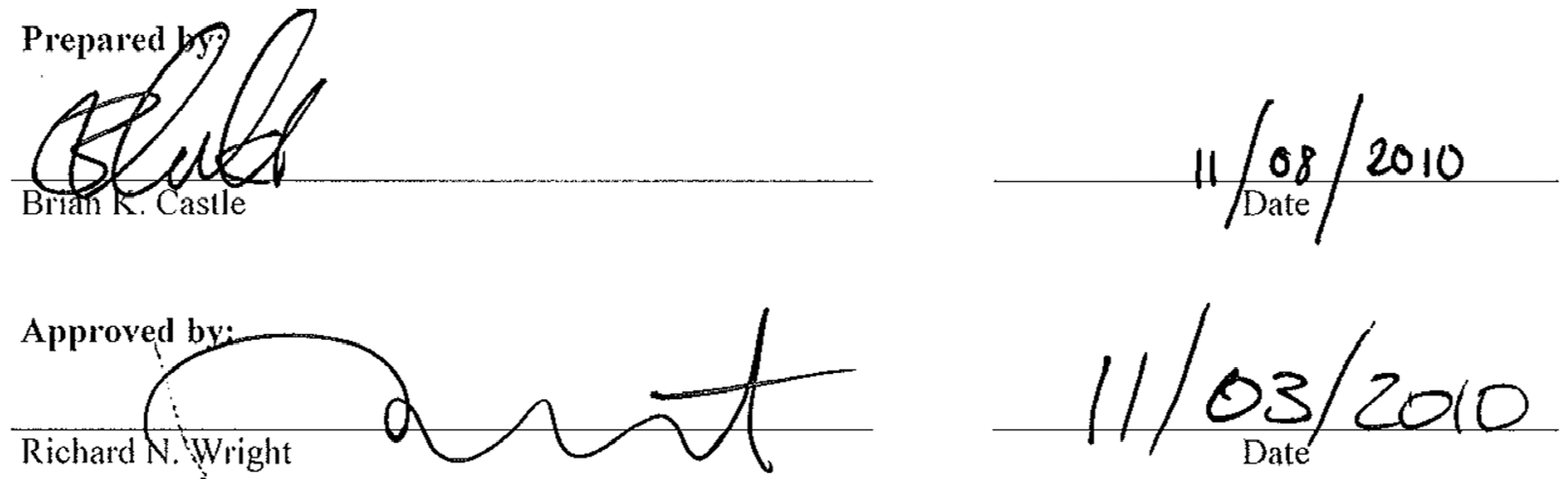

Technical Lèad

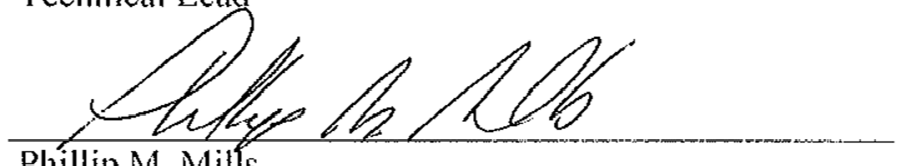

Phillip M. Mills

NGNP Engineering Director (Acting)

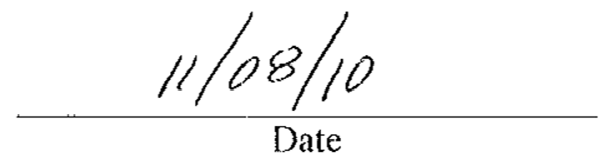





\section{SUMMARY}

The "NGNP Reactor Coolant Chemistry Control Study" has identified the necessary components and the approach used to control the coolant chemistry in high-temperature gas-cooled reactors (HTGR) for eventual use in the Next Generation Nuclear Plant (NGNP). The focus of this study is to determine what technical developments have taken place since previous helium purification systems (HPSs) were operated in previous HTGRs. Since previous HTGR operational experience, a considerable number of corrosion studies have been performed on various high temperature materials in helium environments with various chemistries at elevated temperatures. This newer work has been reviewed and incorporated into this corrosion study to determine how this new information impacts the design requirements for modern HPSs. Research shows that there are ratios of key impurities that determine whether or not a protective oxide layer is formed or if a deleterious relationship is formed between the material and the coolant. These and other influencing factors are taken into consideration when considering the design requirements for the HPS for the NGNP. In addition to the metallic components in the primary circuit, there are other important material considerations that greatly impact the chemistry requirements for the helium coolant, which are the graphite core support structures.

While the metallic components need a small amount of moisture in the coolant to form a protective oxide layer, the graphite needs a very dry environment to prevent degradation. Recommendations and conclusion are made that identify important HPS parameters that should be considered in the design of the HPS for the NGNP.

Following the coolant chemistry control study, it has been determined that additional work is necessary to quantify the impact that the graphite core could have on the purity of the helium coolant, perform more materials testing to better understand the influencing parameters that lead to a controlled oxide growth in the HTGR environments, and to determine the necessary parameters for the use of a coolant chemistry purification system for the water/steam secondary circuit of the NGNP. 


\section{CONTENTS}

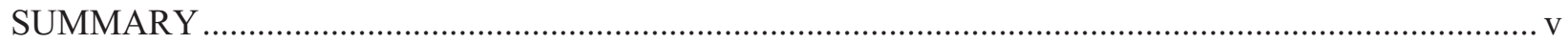

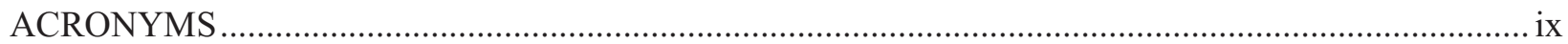

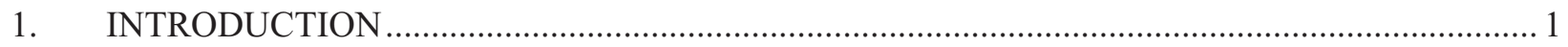

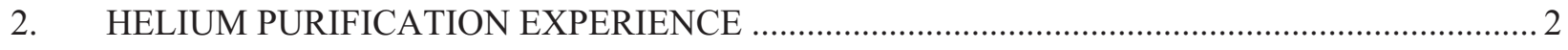

2.1 Peach Bottom Purification System.............................................................................. 2

2.2 Fort St. Vrain Helium Purification System .................................................................... 4

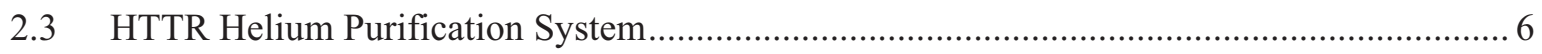

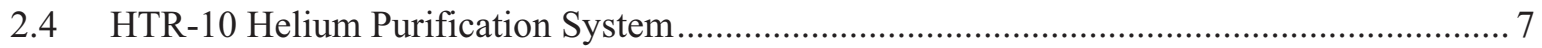

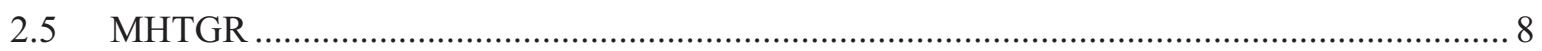

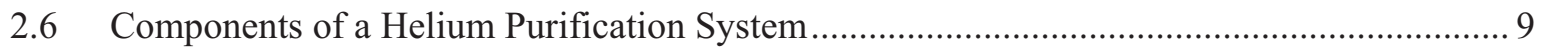

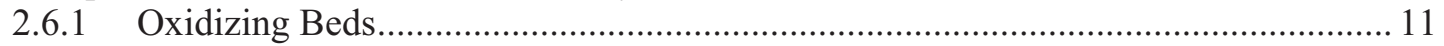

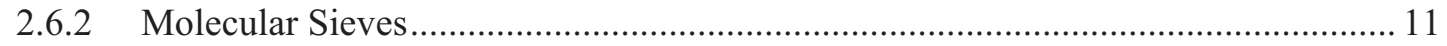

2.6.3 Liquid-Nitrogen-Cooled Charcoal Beds ............................................................. 11

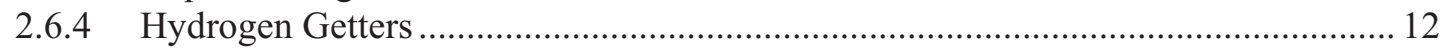

3. EFFECTS OF HELIUM IMPURITIES ON PRIMARY CIRCUIT MATERIALS ........................ 13

3.1 Reactor Design Suppliers' Material Considerations for NGNP Components ...................... 13

3.2 Environmental Influences on Metallic Materials for the NGNP .......................................... 14

3.3 Environmental Influences on Graphite for the NGNP ................................................ 17

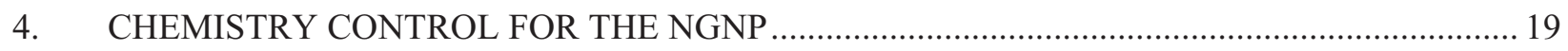

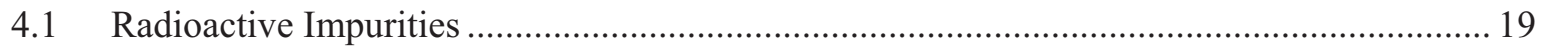

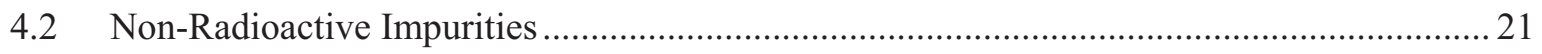

5. APPROACH TO CHEMISTRY CONTROL FOR THE NGNP ….............................................. 24

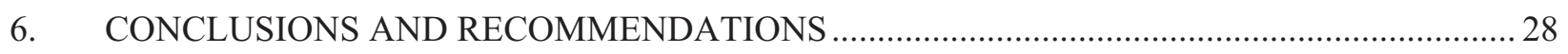

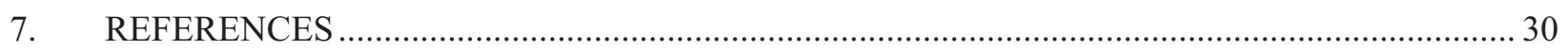

\section{FIGURES}

Figure 1. Schematic of the fission product trapping system, which siphoned off helium from the main loop in the reactor core ${ }^{3}$.

Figure 2. The schematic of the chemical cleanup system that siphoned off helium from the main

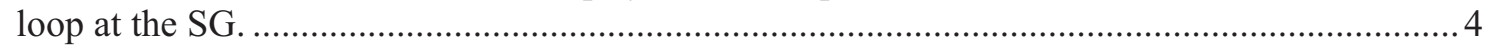

Figure 3. Diagram of Fort St. Vrain's HPS, which also includes the hydrogen getters discussed in

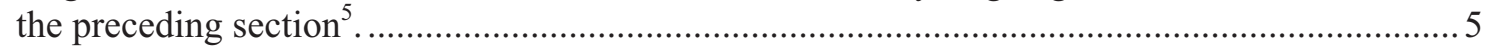

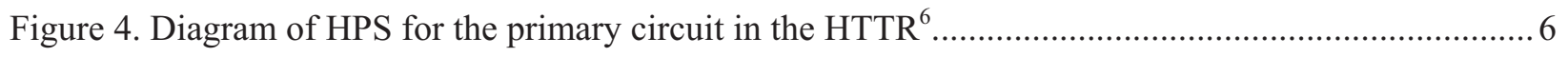

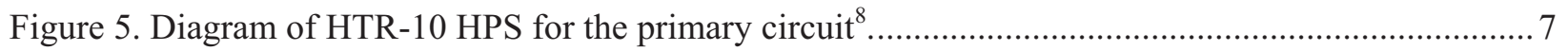


Figure 6. Schematic of the MHTGR HPS ${ }^{12}$.

\section{TABLES}

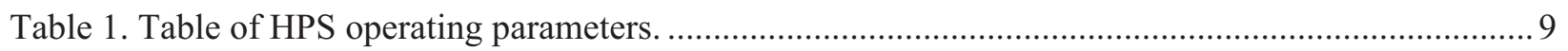

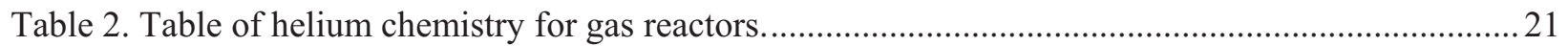

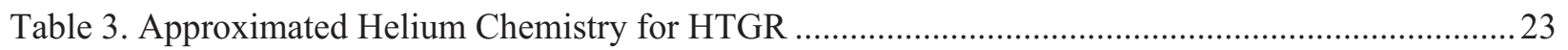

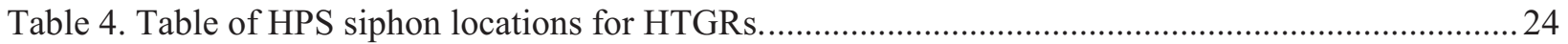




\section{ACRONYMS}

AGR Advanced Gas Reactor

ASME American Society of Mechanical Engineers

AVR

Arbeitsgemeinschaft Versuchsreaktor

B\&PV Boiler and Pressure Vessel

CCS chemical cleanup system

EPA Environmental Protection Agency

FPTS fission-product trapping system

FSV Fort St. Vrain

GA General Atomics

GT-MHR gas-turbine modular high-temperature reactor

HPS helium purification systems

HTGR high-temperature gas-cooled reactor

HTR High Temperature Reactor-10

HTTR High Temperature Engineering Test Reactor

LWR light water reactor

MHTGR modular high-temperature gas-cooled reactor

NGNP Next Generation Nuclear Plant

Ni-Cr-Mo Nickel-chromium-Molybdenum

NOAK nth of a kind

NRC Nuclear Regulatory Commission

R\&D research and development

RPV reactor pressure vessel

SG steam generator

TDRM technical road map document

TRISO tri-structural isotropic

VHTR very high-temperature reactor 


\section{NGNP Reactor Coolant Chemistry Control Study}

\section{INTRODUCTION}

The main focus of this paper is to identify the most desirable ranges of impurity levels in the primary coolant to optimize component life in the primary circuit of the Next Generation Nuclear Plant (NGNP), which will either be a prismatic-block or pebble-bed reactor. There will be a discussion of why the specific impurity levels were selected and the approaches that can be used to control the helium chemistry in the primary loop. The ranges of allowable impurities are based on the most recent information regarding metallic corrosion and graphite corrosion studies in HTGR environments, while considering the previous HTGR operating experience. The corrosion rate in the HTGR is heavily dependent on operating temperatures, the impurity levels of the helium coolant, and the material composition of internal materials. These coolant impurities, when in excessive concentrations at normal operating temperatures of the NGNP, will have increased reactivity with internal structures and without a protective barrier, the structural material will experience a reduction in essential mechanical properties. In HTGRs, helium purification systems (HPSs) are designed to reduce excess concentrations of targeted impurities, such as hydrogen gas, nitrogen gas, carbon-containing molecules, water, and fission products. These impurities, in controlled amounts, can have beneficial effects on the structural materials: high-nickel alloys, low-alloy steels, and graphite. These materials, in an environment with specific concentrations of the aforementioned impurities, form and retain a protective slow-growing stable oxide layer on metallic surfaces, while minimizing the non-beneficial oxidation of graphite structures in the core. The mechanical properties of internal structures, without protective oxide layers at elevated temperatures, can rapidly deteriorate due to the rapid onset of corrosion. The HPS in the primary circuit of the NGNP is designed to minimizing material degradation by maintaining certain impurities within specified ranges and to reduce the radioactive impurities in the primary circuit. 


\section{HELIUM PURIFICATION EXPERIENCE}

The goal of the HPS is to remove impurities from the reactor coolant and to reintroduce very specific quantities of select impurities in order to develop a coolant environment that protects the internal structures of the primary circuit from corrosion. The basic strategy associated with removing impurities from the coolant is to trap the impurities as close to the source as reasonably possible without diluting. ${ }^{13}$ Based on this strategy, two methods have been considered for use in HTGRs. The first strategy involves purifying the entire flow in the circuit as it passes through a specific location in the loop. This would require large equipment to be included in the primary circuit, and it would involve substantial pressure losses due to the flow obstructions that would be necessary to purify the flow. The second strategy involves filtering a fraction of the total helium flow at a time in the primary circuit by siphoning off a small bypass flow that is directed through the HPS. Operational experience has demonstrated the benefits associated with the second strategy of using a bypass flow loop through the HPS. This design is more cost effective than the in-circuit HPSs and using the bypass loop has proven effective. Five HTGR HPSs designs have been reviewed and the main components of these systems have been identified as filters, oxidizers, molecular sieves, charcoal beds, and getters. These components are technologically mature, and no developmental requirements are needed to incorporate this type of system into an NGNP. There is considerable HTGR operational and design experience regarding HPSs, and a brief overview of this experience has been provided along with a brief description of the components used in previous plants. The design considerations and lessons learned in previous plants will be used to inform the NGNP design. Plant instrumentation discussed in previous papers but will be briefly discussed in other sections. ${ }^{1}$

\subsection{Peach Bottom Purification System}

The Peach Bottom plant was a 115-MWth prismatic (40 MWe) power plant that came online in June 1967 and was shut down October 1974. The HPS was successfully operated and was comprised of two independent flow loops called the fission product trapping system (FPTS) and the chemical clean-up system (CCS). These two independent loops siphoned helium from the primary circuit using two purge streams located in the reactor and the steam generator (SG). The FPTS used a set of traps as part of a fission product surveillance effort that was undertaken to determine how much tritium was produced in the core. These traps consisted of activated charcoal and were located in the bottom of fuel elements below the active core. While these traps removed tritium and other fission products, they were primarily in place to provide fission product data. Approximately $750 \mathrm{~kg} / \mathrm{h}$ of helium was withdrawn from the core through the fuel elements and directed through the FPTS. Schematic shown in Figure 1.

After the helium coolant passed through the charcoal traps it was directed through water-cooled charcoal beds then Freon-cooled delay beds. These beds were cooled to $-80^{\circ} \mathrm{C}$, which efficiently removed particulate matter, $\mathrm{H}_{2} \mathrm{O}$, and $\mathrm{CO}_{2}$. Additionally, some amounts of $\mathrm{N}_{2}, \mathrm{CO}$, and $\mathrm{CH}_{4}$ were retained in these beds. It was determined that the water-cooled and Freon-cooled delay beds did not play a significant role in the removal of hydrogen or tritium. The helium leaving the delay beds was directed to the liquid-nitrogen-cooled carbon beds that were operated at temperatures around $-190^{\circ} \mathrm{C}$ and were designed to remove impurities not removed elsewhere, such as $\mathrm{Kr}-85, \mathrm{Ar}, \mathrm{N}_{2}$, and $\mathrm{CH}_{4}$. These beds did not accept the full flow rate of the full bypass system but accommodated a smaller flow stream of 22.7 to $45.4 \mathrm{~kg} / \mathrm{h} .^{2}$ The overflow circumvented the liquid-nitrogen-cooled charcoal bed and was directed downstream. It was determined that the liquid-nitrogen-cooled charcoal bed was extremely effective at removing tritium and most other impurities from the coolant. ${ }^{3}$ 


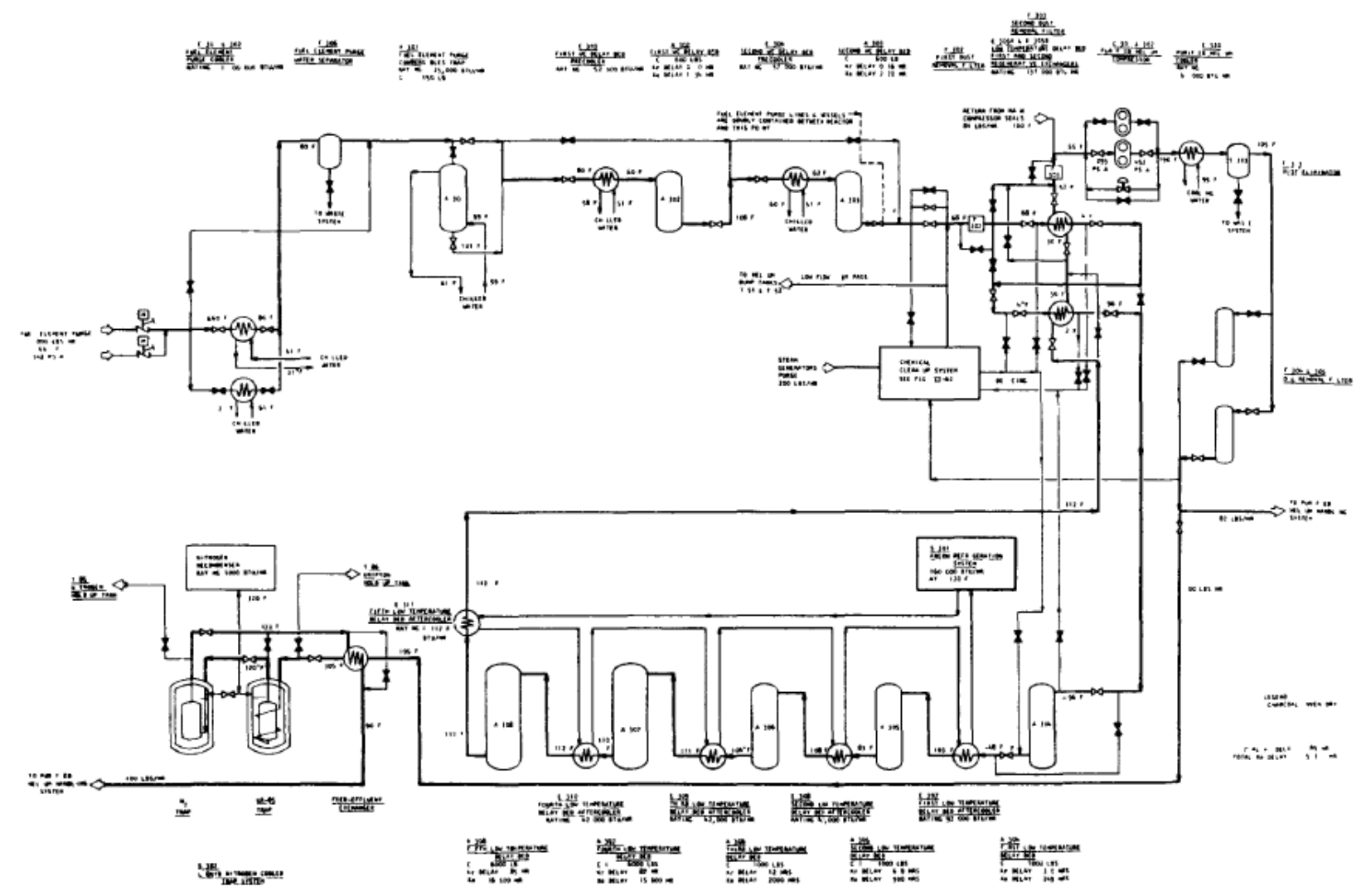

Figure 1. Schematic of the fission product trapping system, which siphoned off helium from the main loop in the reactor core. ${ }^{3}$

The secondary independent purification loop in the primary circuit for the Peach Bottom HPS is the CCS shown in Figure 2, which used a second bypass stream that had a flow rate of $79.4 \mathrm{~kg} / \mathrm{h}$, siphoned from the primary side of the SG. The bypass stream was directed through a copper oxide bed, which oxidized the $\mathrm{CO}$ and $\mathrm{H}_{2}$ to form $\mathrm{CO}_{2}$ and $\mathrm{H}_{2} \mathrm{O}$. The bypass steam then entered a molecular sieve, which bonded the $\mathrm{CO}_{2}$ and $\mathrm{H}_{2} \mathrm{O}$, effectively removing them from the stream. This system effectively removed tritium in the form of tritiated water, as well as other gaseous impurities. The CCS withdrew about 20\%/h of the main helium stream, which effectively removed $\mathrm{H}_{2} \mathrm{O}, \mathrm{H}_{2}, \mathrm{CO}$, and $\mathrm{CO}_{2}$. 


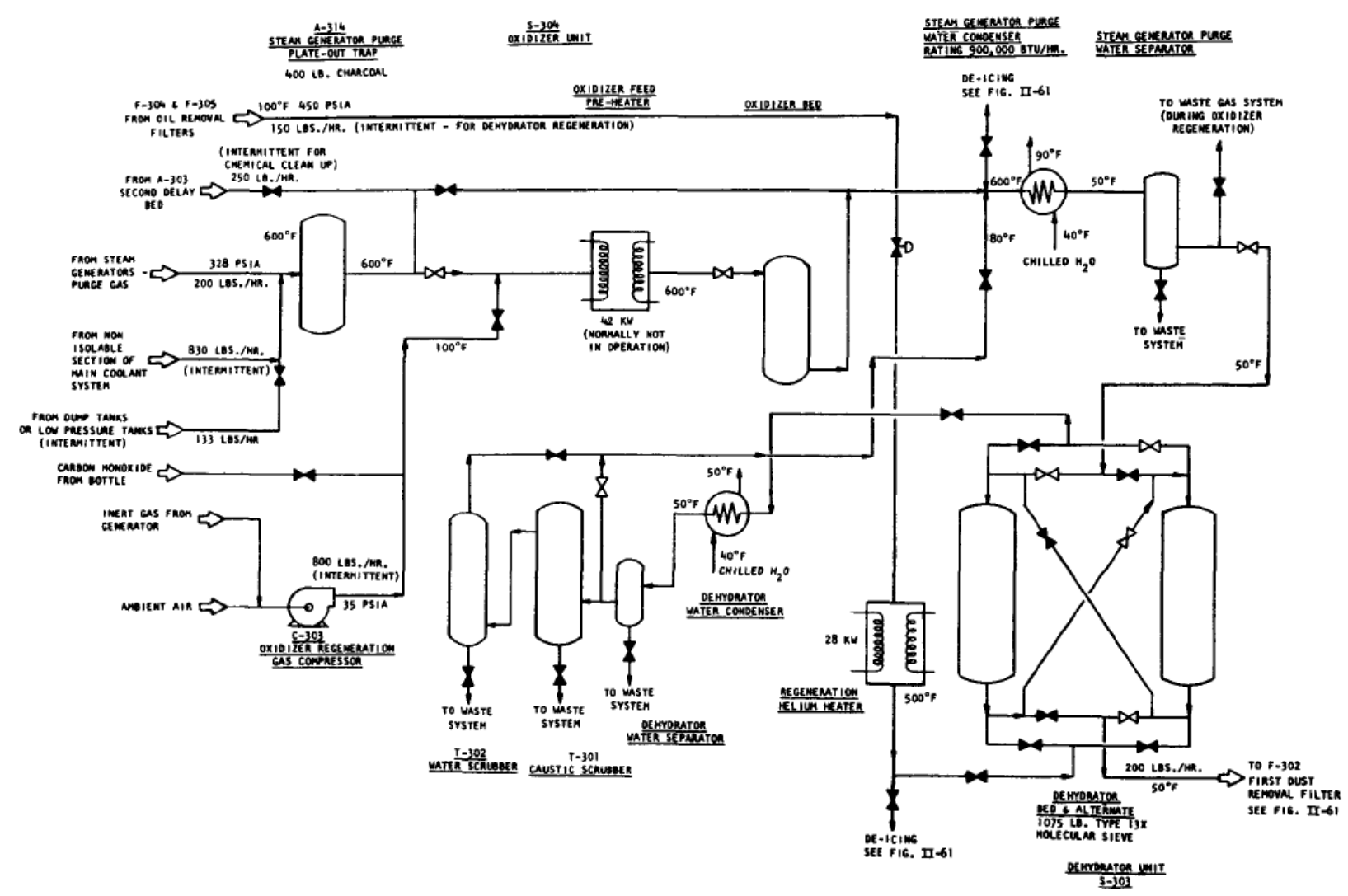

Figure 2. The schematic of the chemical cleanup system that siphoned off helium from the main loop at the $\mathrm{SG}^{3}$

\subsection{Fort St. Vrain Helium Purification System}

Fort Saint Vrain (FSV) was a high-temperature gas-cooled prismatic reactor that produced $842 \mathrm{MWth}$ (330 MWe). FSV experienced considerable water ingress issues, which complicated operations considerably. The FSV HPS was used for purging seals and valves of debris, penetrations for control rod drives of contaminants, and inlet lines; providing buffer gas for the helium circulator; and maintaining an appropriate coolant chemistry to prevent excessive corrosion on internal structures. The HPS was also responsible for purifying helium before it was placed in storage. Despite the considerable amount of water present in the core at various times, the HPS operated well, with a minor exception: titanium tritium getters. A diagram of the FSV HPS is provided below in Figure 3. 


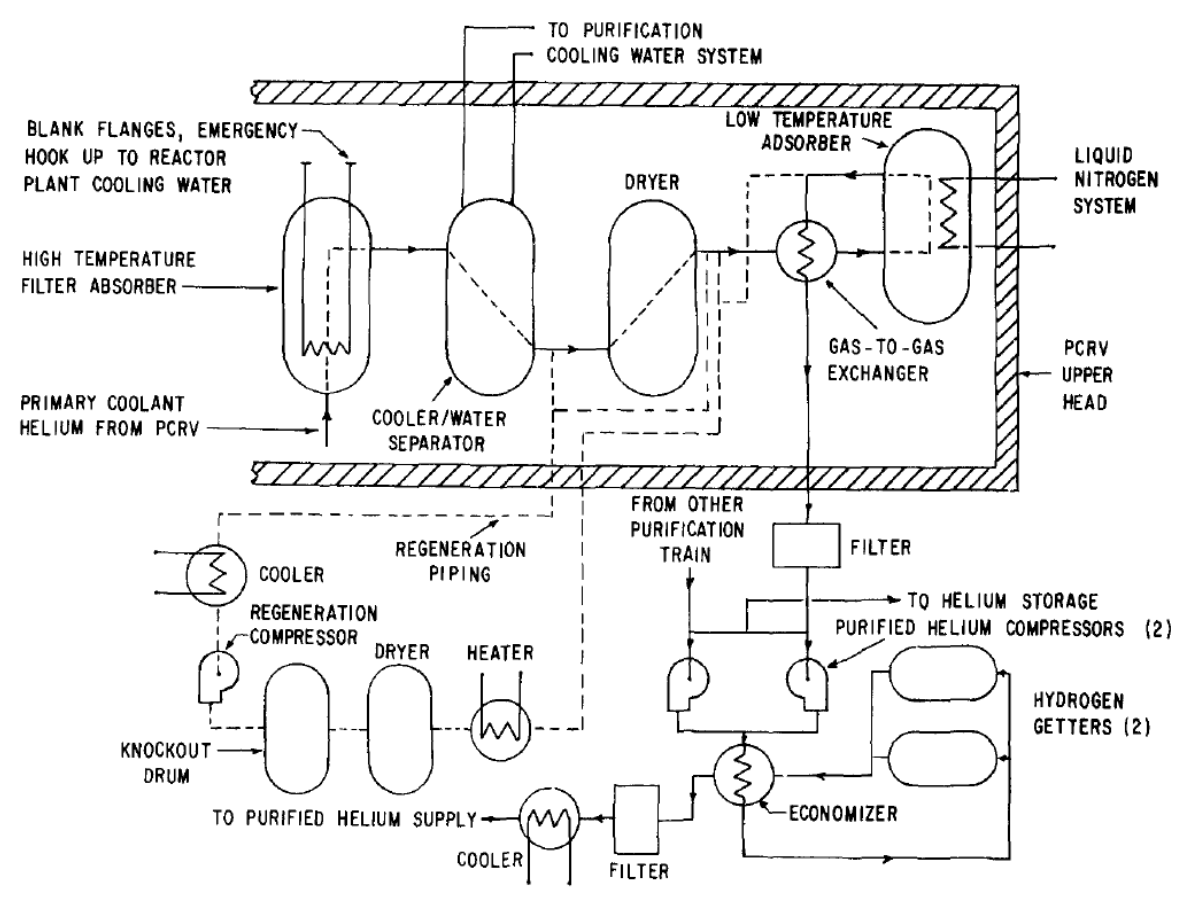

Figure 3. Diagram of Fort St. Vrain's HPS, which also includes the hydrogen getters discussed in the preceding section. ${ }^{5}$

The FSV reactor purified $12 \%$ of the primary coolant per hour by siphoning off a small portion of the primary coolant and sending it through a high-temperature filter after the bypass flow was cooled to $400^{\circ} \mathrm{C}$. The filter was a potassium hydroxide impregnated charcoal adsorber that was designed to remove fission products and particulate matter larger than a few microns. The cool surfaces inside of the filter also made the filter a prime spot for gaseous fission-product plateout. The adsorber bed was maintained below $538^{\circ} \mathrm{C}$ because charcoal loses its adsorptive properties above $538^{\circ} \mathrm{C}$. Some tritium was removed in the adsorber bed. After leaving the high-temperature filter, the bypass stream was then further cooled to $9^{\circ} \mathrm{C}$ prior to entering the cooler/water separator, which condensed the water vapor in the bypass stream and drained the condensate into a liquid waste system. The bypass stream was then passed through a dryer, which used a molecular sieve to remove carbon dioxide and water vapor. Next the bypass stream was cooled to $-182^{\circ} \mathrm{C}$ before entering the liquid nitrogen cooled charcoal trap. Upon entering the liquid-nitrogen-cooled charcoal trap, the helium coolant was further cooled to $-190^{\circ} \mathrm{C}$, which facilitated the adsorption of noble gases, carbon monoxide, nitrogen, methane, and hydrogen/tritium. Following the nitrogen-cooled charcoal trap, the coolant was heated to approximately $40^{\circ} \mathrm{C}$ before it passed through a particle filter, which collected dust from the charcoal beds before reaching the hydrogen getter. The hydrogen getter was a heated titanium sponge that bonded hydroge/tritium to the surface of the metal by forming hydrides. The helium was then heated to approximately $315^{\circ} \mathrm{C}$ before entering the heated getter. Following the getter, the coolant was cooled to $78^{\circ} \mathrm{C}$ and filtered again before its return to the purified helium supply. ${ }^{4}$ The major source of chemical impurities in the helium coolant in the FSV reactor is water vapor reacting with hot graphite, forming $\mathrm{CO}, \mathrm{CO}_{2}$, and $\mathrm{H}_{2}{ }^{5}$ The specified amount of oxidants permitted in the primary coolant was $10 \mathrm{ppm}$, which includes $\mathrm{H}_{2} \mathrm{O}, \mathrm{CO}$, and $\mathrm{CO}_{2}$. The HPS for the FSV reactor had a completely redundant or backup system. One system was continuously operated, while the other system was maintained on standby or undergoing regeneration.

Originally, the FSV HPS was designed to operate for 6 months before regeneration was necessary, but it was later discovered that regeneration was required every 1 to 3 months, depending on the ingress of contaminants. The greater-than-expected regeneration frequency was due to the greater-than-expected 
quantities of impurities in the primary, which mostly consisted of moisture ingresses. The tritium getters were originally designed to be regenerated by heating them above normal operating temperatures to remove adsorbed hydrogen. This procedure was later modified and the tritium sponges were replaced at most all major outages due to their limited effectiveness.

The FSV HPS operated very well with the exception of the titanium sponges. The tritium getters required substantial maintenance and were sporadically in service. ${ }^{5}$ Additionally, the tritium getters were located downstream of the liquid-nitrogen-cooled charcoal beds, which lead to nitrogen gas contamination downstream of the nitrogen beds. The increased amounts of nitrogen gas introduced into the helium further reduced the efficiency of the titanium sponges. No substantial spikes in the tritium concentration recorded due to the problems associated with the titanium sponges. ${ }^{5}$ It was concluded that the tritium was absorbed by the graphite in the core and that the increased circulation time, which gave the tritium time to form tritiated water and tritiated methane before eventual removal.

\subsection{HTTR Helium Purification System}

The High Temperature Engineering Test Reactor (HTTR) is a 30-MWth prismatic test reactor that was primarily designed to investigate nuclear process heat applications and operate with reactor outlet temperatures up to $950^{\circ} \mathrm{C}$. The reactor started operation in 1998 and achieved full power in 2004 . The test reactor has coolant chemistry requirements, like power reactors, but on a much smaller scale. The HPS for the HTTR's primary circuit is shown below in Figure 4.

The HPS for the HTTR uses a bypass stream that siphons off $200 \mathrm{~kg} / \mathrm{h}$ of helium from the auxiliary heat exchanger in the primary circuit and then directs the bypass flow to a particle filter. This flow is then passed through a precharcoal trap that is used to collect gaseous fission products from the coolant stream.

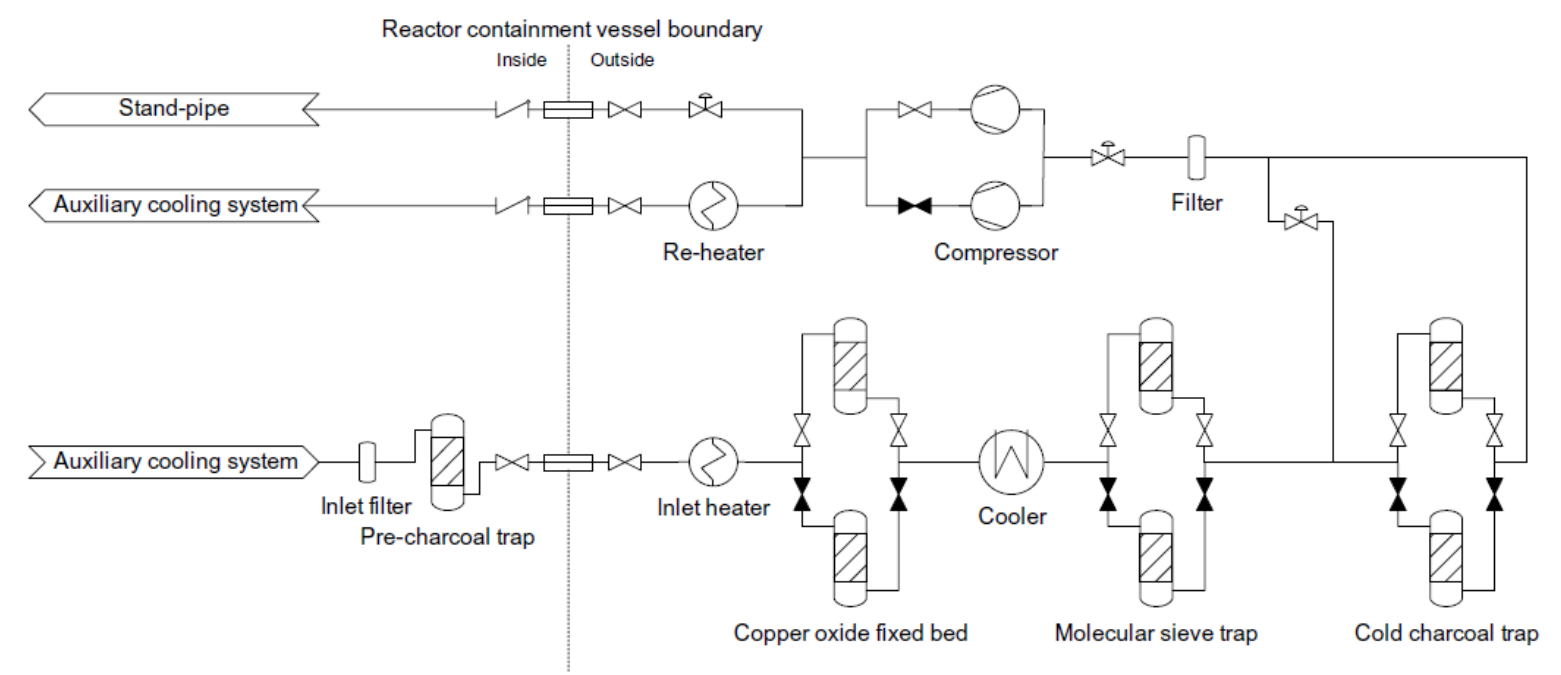

Figure 4. Diagram of HPS for the primary circuit in the HTTR. ${ }^{6}$

The flow is then heated to $280^{\circ} \mathrm{C}$ before it enters the copper oxide catalyst beds, where hydrogen gas and carbon monoxide are oxidized and converted to water vapor and carbon dioxide, respectively. The flow is then cooled and passed through the molecular sieve trap, which captures the water vapor and carbon dioxide by adsorption. The final step of the helium purification process is to pass $50 \mathrm{~kg} / \mathrm{h}$ of helium stream through the cold charcoal trap, which is maintained at $-195^{\circ} \mathrm{C}$, while the remainder of the $200 \mathrm{~kg} / \mathrm{h}$ bypass stream is diverted away from the trap. The charcoal trap removes noble gases, methane, nitrogen, and hydrogen. This provides the HTTR with the capacity to filter more than $10 \%$ of the primary circuit coolant per hour. The primary circuit has redundant traps with the precharcoal trap being the only 
exception. When the traps begin to show reduced efficiencies, they are manually switched to the backup trap and maintenance/regeneration is performed on the problem component. The primary helium purification system has a secondary redundant purification system to ensure coolant chemistry control is maintained during a component failure or regeneration.

The HTTR has a unique approach with regard to the HPS in that the secondary circuit has a dedicated HPS that is almost the same as the primary circuit's HPS. ${ }^{6}$ The secondary circuit's capabilities differ from the primary circuit in two ways. First, the secondary circuit's HPS does not have a precharcoal trap. Secondly, the secondary circuit's HPS was designed to operate with a smaller flow capacity. The mass flow rate of the bypass stream entering the secondary circuit's HPS is $10 \mathrm{~kg} / \mathrm{h},{ }^{7}$ which was pulled from the pressurized water cooler. The secondary circuit's HPS is expected to be an important design consideration for the NGNP due to the interest in minimizing contamination transport to downstream process heat applications.

\subsection{HTR-10 Helium Purification System}

The High Temperature Reactor-10 (HTR-10) is a 10-MWth prototype pebble-bed reactor that started operation in 2003 . The reactor is designed to operate with a reactor output temperature above $700^{\circ} \mathrm{C}$. Figure 5 shows a diagram of the HPS for the HTR-10. During normal operation the primary coolant from the reactor is passed through a 5-micron cartridge filter that removes particulate matter. The helium purification system is designed to purify $5 \%$ of the primary coolant every hour, which corresponds to $10.5 \mathrm{~kg} / \mathrm{h}$ of helium. ${ }^{8}$ The helium coolant is then heated to $250^{\circ} \mathrm{C}$ before being directed through a copper oxide bed. The stream is then further filtered for dust and passed through a water cooler. The moisture in the stream is removed by a moisture separator. The liquid removed from the moisture separator will likely contain tritiated water and is disposed of as radioactive liquid waste. The helium coolant is then directed through a molecular sieve absorber, operating at room temperature, which removes water vapor and carbon dioxide. The bypass stream is finally passed through a liquid nitrogen absorber, which is a cold charcoal trap that operates at $-160^{\circ} \mathrm{C}$. The liquid nitrogen trap captures noble gases, methane, oxygen, and nitrogen. ${ }^{9,10}$ The HPS for the HTR-10 is designed for frequent regeneration. The copper oxide bed is designed to be regenerated every 2000 hours of operation.

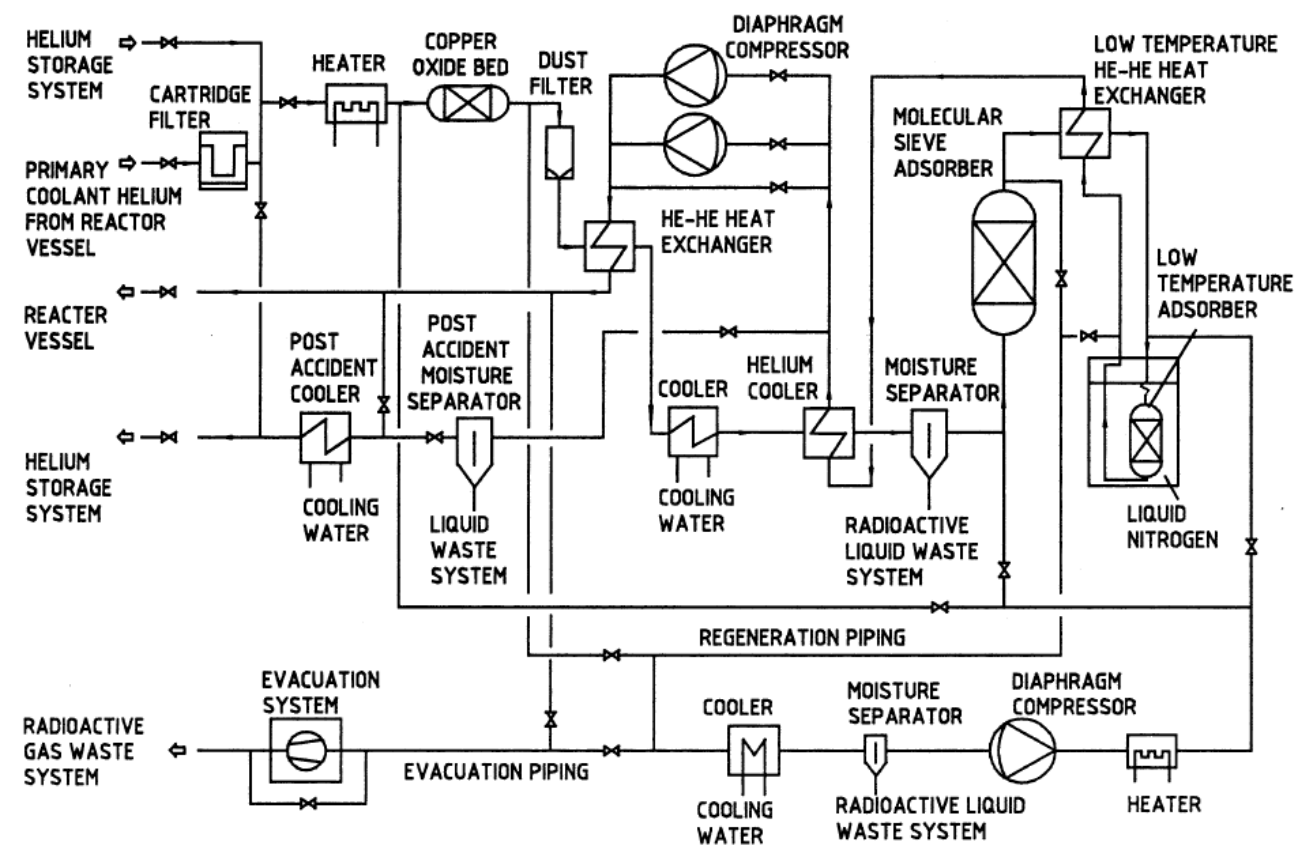

Figure 5. Diagram of HTR-10 HPS for the primary circuit. ${ }^{8}$ 


\section{$2.5 \quad$ MHTGR}

The modular high-temperature gas-cooled reactor (MHTGR) is a design for a helium-cooled prismatic reactor. The reactor was designed to operate with four identical modules with a thermal power of $350 \mathrm{MWth}$ each. The core outlet temperature for this reactor was designed to be $687^{\circ} \mathrm{C}$, maintain a pressure of $6.4 \mathrm{MPa}$, and operate on a steam cycle.

The HPSs for the MHTGR and the gas-turbine modular high-temperature reactor (GT-MHR) are very similar and consequently, both HPSs designs for these reactors are discussed together. The HPS used in these reactors, at the stated power, will remove about $386 \mathrm{~kg} / \mathrm{hr}$ (GT-MHR) of helium to be purified. The purified helium enters high-temperature adsorbers, which removes iodine, bromine, and other metallic fission products. The flow stream is then filtered of particulate matter. The flow stream passes through an oxidizer and water cooler. The hydrogen gas and carbon monoxide are oxidized and the water cooler, which operates around $38^{\circ} \mathrm{C}$, is used to remove water and carbon dioxide. ${ }^{33}$ The final destination of the flow is the low-temperature adsorbers, where liquid nitrogen is used to cool the charcoal beds down to $-196^{\circ} \mathrm{C}$ to remove noble gases and other fission products. The purified helium flow is then redirected to the helium transfer and storage system. This system uses a helium transfer compressor to pressurize the high-pressure storage tanks and to pump helium into the primary circuit. If the helium needs to be reintroduced into the primary circuit, the transfer compressor injects the helium through the inlet of the primary circuit's precooler, as well as at other locations. Smaller streams of purified helium are also directed to turbomachinery seals, vessel seals, and vessel pressure relief piping. ${ }^{11}$

The HPS for the MHTGR, shown in Figure 6, is designed to operate within a flow range of 0 to $1455 \mathrm{~kg} / \mathrm{hr}$. The maximum throughput is used during initial startup, which requires the entire inventory of the primary coolant to be processed through the HPS. It is important to initially purify the helium, which will become increasingly contaminated with the off-gassing graphite due to the increasing reactor temperature. In addition, in the event of a rapid depressurization, the HPS will operate at the maximum throughput speeds and store the processed coolant in the storage system. The normal flow rate through the HPS is $386 \mathrm{~kg} / \mathrm{hr}$, and it can be operated under normal circumstances at up to 4 times the normal operational flow rate during scheduled refueling and maintenance. During normal operation, the HPS operates at near-constant volumetric flow rates. The HPS is also designed to operate over a pressure range of $0-6.38 \mathrm{MPa}$, with a coolant pressure of $6.4 \mathrm{MPa}$ in the primary circuit. ${ }^{12}$

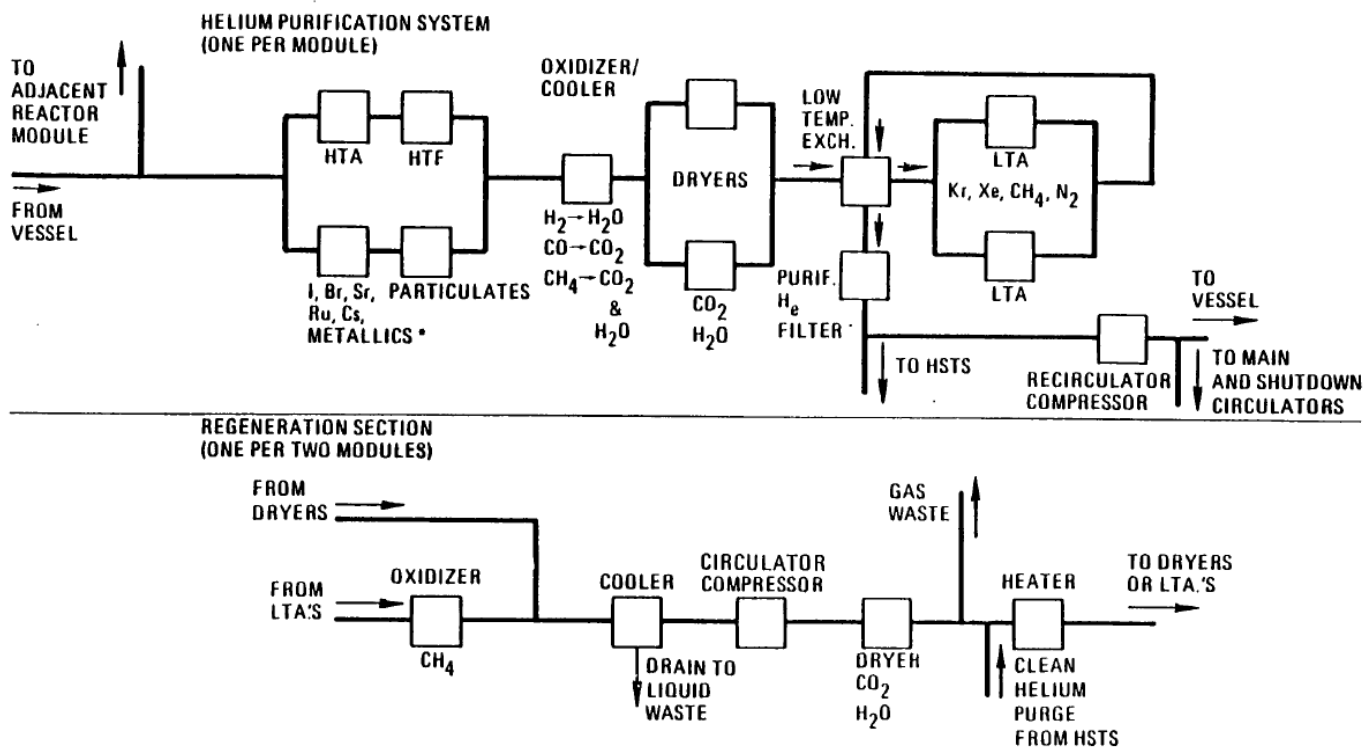

Figure 6. Schematic of the MHTGR HPS. ${ }^{12}$ 


\subsection{Components of a Helium Purification System}

Each of the five reactors discussed above have used similar components to operate their HPS. Table 1 shows the components used in each reactor system to emphasize the similarities and differences between the systems. Five different kinds of mechanisms helped remove impurities. The first removal mechanism is the filter/adsorber, which is used to remove particulate matter that is operated at significantly lower than reactor outlet temperatures, thus providing a place for plateout of long-lived fission products. The second removal mechanism is the oxidizer, which attaches an oxygen atom to impurities. By oxidizing specific atoms/molecules, such as hydrogen gas and carbon monoxide, the difficulties associated with their removal are greatly decreased. The third mechanism used to remove impurities is the molecular sieve. This component chemically bonds various impurities and retains the impurities until the component is regenerated. The fourth removal method is the charcoal bed, which is used to remove impurities by trapping them to charcoal. Reducing the temperature increases the effectiveness of the beds, which increases the impurity removal rates. The charcoal is often chemically activated or doped, which further increases the charcoal's effectiveness. The fifth and final removal mechanism demonstrated in these systems is gettering. This method targets a specific substance for bonding, like tritium. It was determined that hydrogen getters were highly ineffective in FSV, and it is expected that hydrogen getters will not be used again in future HPSs. FSV's difficulties were a result of significant quantities of nitrogen gas and water vapor deactivating the Ti beds.

The five HPS designs discussed above have very similar designs and components. In Table 1, descriptions of each of the HPSs are provided to show their similarities and differences between the HPSs.

Distinct similarities between the HPSs are shown in Table 1. Each system uses virtually the same components at around the same operating parameters, with only two glaring exceptions. These differences are the HPS used on the secondary circuit of the HTTR and the use of the titanium tritium getters used in FSV. These HPSs have these differences not seen in the others. The HPS in the secondary circuit is used to provide a very clean heat source that transports a very low amount of tritium to the intended heat application, which is a special requirement based on the intended use of the reactor itself. FSV's use of the titanium getters was an attempt to remove tritium from the primary circuit by using a new component in their HPS, which was later determined to be ineffective. The continued use of this component in HTGR is not expected.

Table 1. Table of HPS operating parameters.

\begin{tabular}{|c|c|c|c|c|c|c|c|}
\hline $\begin{array}{c}\text { Reactor } \\
\text { Name }\end{array}$ & $\begin{array}{c}\text { Component or } \\
\text { Subsystem }\end{array}$ & Operation Performed & $\begin{array}{c}\text { Reaction } \\
\text { type }\end{array}$ & $\begin{array}{l}\text { Temperature } \\
\text { of operation }\end{array}$ & $\begin{array}{c}\text { Bypass flow } \\
\text { rate }\end{array}$ & $\begin{array}{l}\text { \% of Bypass } \\
\text { flow in HPS } \\
\end{array}$ & $\begin{array}{c}\text { Location in the } \\
\text { plant }\end{array}$ \\
\hline \multirow[t]{9}{*}{ HTTR } & Particle filter & $\begin{array}{l}\text { Mechanically remove } \\
\text { debris }\end{array}$ & $\begin{array}{l}\begin{array}{l}\text { Filter \& } \\
\text { plateout }\end{array} \\
\end{array}$ & $<280^{\circ} \mathrm{C}$ & $200 \mathrm{~kg} / \mathrm{h}$ & $10 \% / \mathrm{h}$ & Primary circuit \\
\hline & Precharcoal trap & Gaseous fission products & Adsorption & $280^{\circ} \mathrm{C}$ & $200 \mathrm{~kg} / \mathrm{h}$ & $10 \% / \mathrm{h}$ & Primary circuit \\
\hline & $\begin{array}{l}\text { Copper-oxide } \\
\text { catalyst beds }\end{array}$ & $\begin{array}{l}\mathrm{H} \text { and } \mathrm{CO} \text { are converted to } \\
\mathrm{H}_{2} \mathrm{O} \text { and } \mathrm{CO}_{2}\end{array}$ & Oxidation & $280^{\circ} \mathrm{C}$ & $200 \mathrm{~kg} / \mathrm{h}$ & $10 \% / \mathrm{h}$ & Primary circuit \\
\hline & Molecular sieve trap & Captures $\mathrm{H}_{2} \mathrm{O}$ and $\mathrm{CO}_{2}$ & Adsorption & $<280^{\circ} \mathrm{C}$ & $200 \mathrm{~kg} / \mathrm{h}$ & $10 \% / \mathrm{h}$ & Primary circuit \\
\hline & Cold charcoal trap & $\begin{array}{l}\text { Noble gases, methane, } \\
\text { nitrogen, and hydrogen }\end{array}$ & Adsorption & $-195^{\circ} \mathrm{C}$ & $50 \mathrm{~kg} / \mathrm{h}$ & $\sim 2.5 \% / \mathrm{h}$ & Primary circuit \\
\hline & Particle filter & $\begin{array}{l}\text { Mechanically remove } \\
\text { debris }\end{array}$ & $\begin{array}{l}\text { Filter \& } \\
\text { plateout }\end{array}$ & $<280^{\circ} \mathrm{C}$ & $10 \mathrm{~kg} / \mathrm{h}$ & - & Secondary circuit \\
\hline & $\begin{array}{l}\text { Copper-oxide } \\
\text { catalyst beds }\end{array}$ & $\begin{array}{l}\mathrm{H} \text { and } \mathrm{CO} \text { are converted to } \\
\mathrm{H}_{2} \mathrm{O} \text { and } \mathrm{CO}_{2}\end{array}$ & Oxidation & - & $10 \mathrm{~kg} / \mathrm{h}$ & - & Secondary circuit \\
\hline & Molecular sieve trap & Captures $\mathrm{H}_{2} \mathrm{O}$ and $\mathrm{CO}_{2}$ & Adsorption & $<280^{\circ} \mathrm{C}$ & $10 \mathrm{~kg} / \mathrm{h}$ & - & Secondary circuit \\
\hline & Cold Charcoal Trap & $\begin{array}{l}\text { Noble gases, methane, } \\
\text { nitrogen, and hydrogen }\end{array}$ & Adsorption & $-195^{\circ} \mathrm{C}$ & $10 \mathrm{~kg} / \mathrm{h}$ & - & Secondary circuit \\
\hline HTR-10 & Cartridge filter & $\begin{array}{l}\text { Particle larger than } 5 \\
\text { microns }\end{array}$ & $\begin{array}{l}\text { Filter \& } \\
\text { plateout }\end{array}$ & $250^{\circ} \mathrm{C}$ & - & - & - \\
\hline
\end{tabular}




\begin{tabular}{|c|c|c|c|c|c|c|c|}
\hline $\begin{array}{c}\text { Reactor } \\
\text { Name }\end{array}$ & $\begin{array}{c}\text { Component or } \\
\text { Subsystem } \\
\end{array}$ & Operation Performed & $\begin{array}{c}\text { Reaction } \\
\text { type }\end{array}$ & $\begin{array}{c}\text { Temperature } \\
\text { of operation }\end{array}$ & $\begin{array}{l}\text { Bypass flow } \\
\text { rate } \\
\end{array}$ & $\begin{array}{l}\text { \% of Bypass } \\
\text { flow in HPS }\end{array}$ & $\begin{array}{c}\text { Location in the } \\
\text { plant }\end{array}$ \\
\hline & Copper-oxide bed & $\begin{array}{l}\mathrm{H} \text { and } \mathrm{CO} \text { are converted to } \\
\mathrm{H}_{2} \mathrm{O} \text { and } \mathrm{CO}_{2}\end{array}$ & Oxidation & $250^{\circ} \mathrm{C}$ & $10.5 \mathrm{~kg} / \mathrm{h}$ & $5 \% / \mathrm{h}$ & Primary circuit \\
\hline & $\begin{array}{l}\text { Molecular sieve } \\
\text { adsorber }\end{array}$ & Captures $\mathrm{H}_{2} \mathrm{O}$ and $\mathrm{CO}_{2}$ & Adsorption & $\begin{array}{c}\sim \text { room } \\
\text { temperature }\end{array}$ & $10.5 \mathrm{~kg} / \mathrm{h}$ & $5 \% / h$ & Primary circuit \\
\hline & $\begin{array}{l}\text { Low-temperature } \\
\text { adsorber }\end{array}$ & $\begin{array}{l}\text { Methane, oxygen, nitrogen, } \\
\text { noble gases like krypton, } \\
\text { and xenon }\end{array}$ & Adsorption & $-160^{\circ} \mathrm{C}$ & $10.5 \mathrm{~kg} / \mathrm{h}$ & $5 \% / h$ & Primary circuit \\
\hline \multirow[t]{5}{*}{$\begin{array}{l}\text { Peach } \\
\text { Bottom }\end{array}$} & $\begin{array}{l}\text { Water-cooled active } \\
\text { charcoal traps } \\
\text { (independent) }\end{array}$ & $\begin{array}{l}\text { Noble gases, methane, } \\
\text { nitrogen, and hydrogen }\end{array}$ & Adsorption & - & $340 \mathrm{~kg} / \mathrm{h}$ & $80 \% / \mathrm{h}$ & $\begin{array}{l}\text { Primary circuit- } \\
\text { fission product } \\
\text { trapping system, } \\
\text { taken from core } \\
\end{array}$ \\
\hline & $\begin{array}{l}\text { Freon cooled delay } \\
\text { beds }\end{array}$ & $\begin{array}{l}\text { Fission gases, hydrogen, } \\
\text { nitrogen, carbon monoxide, } \\
\text { methane }\end{array}$ & Adsorption & $-80^{\circ} \mathrm{C}$ & $340 \mathrm{~kg} / \mathrm{h}$ & $80 \% / \mathrm{h}$ & $\begin{array}{l}\text { Primary circuit- } \\
\text { fission product } \\
\text { trapping system, } \\
\text { taken from core } \\
\end{array}$ \\
\hline & $\begin{array}{l}\text { Liquid-nitrogen- } \\
\text { cooled carbon bed }\end{array}$ & $\begin{array}{l}\text { Removes all gas impurities } \\
\text { especially argon, nitrogen, } \\
\text { methane, krypton- } 85 \text {, and } \\
\text { doesn't remove hydrogen } \\
\text { and neon } \\
\end{array}$ & Adsorption & - & $22-45 \mathrm{~kg} / \mathrm{h}$ & $10.6 \% / h$ & $\begin{array}{l}\text { Primary circuit- } \\
\text { fission product } \\
\text { trapping system, } \\
\text { taken from core }\end{array}$ \\
\hline & Copper-oxide bed & $\begin{array}{l}\mathrm{H} \text { and } \mathrm{CO} \text { are converted to } \\
\mathrm{H}_{2} \mathrm{O} \text { and } \mathrm{CO}_{2}\end{array}$ & Oxidation & - & $79 \mathrm{~kg} / \mathrm{h}$ & $20 \% / \mathrm{h}$ & $\begin{array}{l}\text { Primary circuit, } \\
\text { chemical } \\
\text { purification system, } \\
\text { taken from SG } \\
\end{array}$ \\
\hline & $\begin{array}{l}\text { Molecular Sieve } \\
\text { Trap }\end{array}$ & Captures $\mathrm{H}_{2} \mathrm{O}$ and $\mathrm{CO}_{2}$ & Adsorption & - & $79 \mathrm{~kg} / \mathrm{h}$ & $20 \% / h$ & $\begin{array}{l}\text { Primary circuit, } \\
\text { chemical } \\
\text { purification system, } \\
\text { taken from SG } \\
\end{array}$ \\
\hline \multirow[t]{7}{*}{ FSV } & $\begin{array}{l}\text { High-temperature } \\
\text { filter, potassium } \\
\text { impregnated } \\
\text { charcoal adsorber } \\
\end{array}$ & $\begin{array}{l}\text { Fission products, noble } \\
\text { gases }\end{array}$ & $\begin{array}{l}\text { Filter \& } \\
\text { plateout }\end{array}$ & $400^{\circ} \mathrm{C}$ & $\begin{array}{c}1.85 \times 10^{5} \\
\mathrm{~kg} / \mathrm{h}\end{array}$ & $12 \% / \mathrm{h}$ & Primary circuit \\
\hline & $\begin{array}{l}\text { Cooler/water } \\
\text { separator }\end{array}$ & $\mathrm{H}_{2} \mathrm{O}$ & - & $48^{\circ} \mathrm{C}$ & $\begin{array}{c}1.85 \times 10^{5} \\
\mathrm{~kg} / \mathrm{h}\end{array}$ & $12 \% / \mathrm{h}$ & Primary circuit \\
\hline & $\begin{array}{l}\text { Dryer/ molecular } \\
\text { sieve }\end{array}$ & $\mathrm{CO}_{2}$ and $\mathrm{H}_{2} \mathrm{O}$ & Adsorption & $48^{\circ} \mathrm{C}$ & $\begin{array}{c}1.85 \times 10^{5} \\
\mathrm{~kg} / \mathrm{h}\end{array}$ & $12 \% / \mathrm{h}$ & Primary circuit \\
\hline & $\begin{array}{l}\text { Cooled nitrogen } \\
\text { trap }\end{array}$ & $\begin{array}{l}\text { Noble gases, carbon } \\
\text { monoxide, nitrogen, } \\
\text { methane, hydrogen }\end{array}$ & Adsorption & $\begin{array}{l}\text { Entered at } \\
-295^{\circ} \mathrm{C} \text { and } \\
\text { cooled to } \\
-310^{\circ} \mathrm{C} \\
\end{array}$ & $\begin{array}{c}1.85 \times 10^{5} \\
\mathrm{~kg} / \mathrm{h}\end{array}$ & $12 \% / \mathrm{h}$ & Primary circuit \\
\hline & Particle filter & $\begin{array}{l}\text { Mechanically remove } \\
\text { debris }\end{array}$ & $\begin{array}{l}\text { Filter \& } \\
\text { plateout }\end{array}$ & $40^{\circ} \mathrm{C}$ & $\begin{array}{c}1.85 \times 10^{5} \\
\mathrm{~kg} / \mathrm{h}\end{array}$ & $12 \% / \mathrm{h}$ & Primary circuit \\
\hline & Hydrogen Sponge & - & - & $315^{\circ} \mathrm{C}$ & $\begin{array}{c}1.85 \times 10^{5} \\
\mathrm{~kg} / \mathrm{h}\end{array}$ & $12 \% / \mathrm{h}$ & Primary circuit \\
\hline & Filter & $\begin{array}{l}\text { Mechanically remove } \\
\text { debris }\end{array}$ & Filter & $78^{\circ} \mathrm{C}$ & $\begin{array}{c}1.85 \times 10^{5} \\
\mathrm{~kg} / \mathrm{h}\end{array}$ & $12 \% / \mathrm{h}$ & Primary circuit \\
\hline \multirow[t]{4}{*}{ MHTGR } & $\begin{array}{l}\text { High-temperature } \\
\text { adsorber }\end{array}$ & $\begin{array}{l}\text { Removes iodine, bromine, } \\
\text { and other metallic fission } \\
\text { products }\end{array}$ & $\begin{array}{l}\text { Filter \& } \\
\text { plateout }\end{array}$ & $107^{\circ} \mathrm{C}$ & $386 \mathrm{~kg} / \mathrm{hr}$ & $\sim 0.07 \% / \mathrm{h}$ & Primary circuit \\
\hline & $\mathrm{CuO}$, oxidizer & $\begin{array}{l}\mathrm{H} \text { and } \mathrm{CO} \text { are converted to } \\
\mathrm{H}_{2} \mathrm{O} \text { and } \mathrm{CO}_{2}\end{array}$ & Oxidation & - & $386 \mathrm{~kg} / \mathrm{hr}$ & $\sim 0.07 \% / \mathrm{h}$ & Primary circuit \\
\hline & Water cooler & - & Adsorption & $38^{\circ} \mathrm{C}$ & $386 \mathrm{~kg} / \mathrm{hr}$ & $\sim 0.07 \% / \mathrm{h}$ & Primary circuit \\
\hline & $\begin{array}{l}\text { Low-temperature } \\
\text { adsorber }\end{array}$ & $\begin{array}{l}\text { Removes noble gases and } \\
\text { other fission products }\end{array}$ & Adsorption & $-196^{\circ} \mathrm{C}$ & $386 \mathrm{~kg} / \mathrm{hr}$ & $\sim 0.07 \% / \mathrm{h}$ & Primary circuit \\
\hline
\end{tabular}

Each of the aforementioned HPS components have specific capabilities and parameters of operation, which are briefly discussed to elucidate the operation of each component and the HPS as a whole. 


\subsubsection{Oxidizing Beds}

Oxidizing beds use chemical reactions to chemically bond oxygen to reactive species that pass through the beds. The beds are filled with an oxidizing agent like copper oxide. The oxidizing agent is in a form that will allow a flowing gas to pass through the bed with limited impedance, i.e., small spheres or unformed chunks. In the HPS the oxidizing beds are usually used to oxidize hydrogen gas and carbon monoxide to produce water and carbon dioxide. In HTGRs, tritium is a common contaminant that can be readily oxidized to form tritiated water. This is the preferred form of tritium because it is more chemically stable and more easily removed from the helium coolant and contained than gaseous tritium. The oxidation of carbon monoxide is also a favorable reaction because it produces carbon dioxide, which is more easily removed by a molecular sieve that carbon monoxide.

Operating temperature is an important factor when using an oxidizing agent because some catalysts are less useful in some temperature ranges. For temperatures around $200^{\circ} \mathrm{C}$, copper oxide is a favorable oxidizing agent. At higher operating temperatures, above $200^{\circ} \mathrm{C}, \mathrm{MnO}_{2}$ and $\mathrm{Fe}_{2} \mathrm{O}_{3}$ are more suitable oxidizing agents. ${ }^{14}$

The oxidizing beds are oxygen rich, and when this oxygen begins to be depleted due to transferring oxygen to impurities, the effectiveness of the beds is greatly reduced. This can be determined by sensors that measure contaminants, which are located at the entrance and exit of the beds. When the efficiency of the beds is determined to be below a set limit, a regeneration process takes place to recharge the oxygen content of the beds. The frequency for regeneration depends on the amount of impurities passing through the bed, operating temperature, mass flow rate through the bed, and the size of the bed.

In the regeneration process, the temperature of the bed is often reduced along with the pressure. A steady concentration of oxygen is injected into the system for an extended period of time, effectively replenishing the oxygen content of the beds. In modern plants, like the HTR-10, regeneration is scheduled for every 2000 hours of operation. ${ }^{8}$

\subsubsection{Molecular Sieves}

The molecular sieve bed is made of small-diameter spherical adsorbing material that will be packed into a corrosion-resistant container that will have the helium coolant pass through it. Several commercially available materials exist that chemically bond water and carbon dioxide, as well as other materials, to the absorbing spheres. Different bonding materials have different chemical characteristics, including different bonding capabilities regarding critical diameters of molecules that can be captured and retained. ${ }^{15}$

When these components begin to operate with reduced efficiency, they are regenerated. Regeneration for a molecular sieve is accomplished by reducing the pressure around the trap and heating it to temperatures above the normal operating temperatures. The elevated temperature is maintained for an extended period of time until the carbon dioxide and water are extracted.

\subsubsection{Liquid-Nitrogen-Cooled Charcoal Beds}

Cooled charcoal beds have several mechanisms used to remove impurities from the coolant stream, such as filtration, chemisorption, and plateout. The carbon used in these beds is activated, which means that a chemical active ingredient has been added. In HTGRs, potassium-impregnated charcoal adsorbing material has been frequently used. Charcoal beds are particularly effective at removing fission products below $-70^{\circ} \mathrm{C}$. By cooling the charcoal beds to very low temperatures, the beds effectively remove hydrogen from the helium coolant. At very low temperatures, around $-190^{\circ} \mathrm{C}$, many noble gases are removed from the coolant. At temperatures between $-70^{\circ} \mathrm{C}$ and $300^{\circ} \mathrm{C}$, little adsorption occurs. ${ }^{3}$ 
When these traps become full of removed contaminants and have reduced effectiveness, they are regenerated. This occurs by isolating the system and allowing it to warm up. The contaminants that have been collected are released, collected, and disposed of.

\subsubsection{Hydrogen Getters}

Tritium and tritiated compounds can be removed from helium coolant by gettering and chemical transformation and capture. Gettering often involves the use of a base metal, such as titanium, that can dissolve hydrogen and form metal-hydrogen phases or hydrides within the base metal. Hydrogen getters use base metals that strongly bond with hydrogen and have a low equilibrium pressure of hydrogen at the operating temperature. Other materials have been identified as good potential base materials for getters: zirconium, lanthanum, cerium, yttrium, and uranium. Material cost is a major consideration for use in hydrogen getters.

Once the base metal dissolves hydrogen and a hydride is formed, the bond is quite strong. Hydrides form exothermically, often at somewhat lower temperatures, and become unstable at higher temperatures. Hydrogen diffuses into metals, driven by the concentration gradients and temperature gradients. When the terminal solid solubility of hydrogen in a metal is reached, hydrides often precipitate in regions of stress concentrations. ${ }^{16}$ Terminal solid solubility for hydrogen is greater at higher temperatures, which suggests that temperature fluctuations in areas of high hydrogen content may increase the formation of hydrides. Hydrides are generally very brittle, and induced stresses readily cause crack generation and propagation. ${ }^{17}$ The cracks that are formed in the hydrides are beneficial in the base metals of getters, because these cracks potentially allow hydrogen to travel down the cracks and contact the base metal, which can then form more hydrides. This is beneficial if the goal is to capture more hydrogen. If a metallic structure forms internal hydrides and it is not the goal of the material to capture and retain hydrogen, the corrosion process is called hydrogen embrittlement.

Hydrides are unstable at elevated temperatures; this attribute is used to "recharge" the system and increase the getters' effectiveness by releasing the bonded hydrogen. After prolonged operation, getters become less effective because of the built-up hydride layers that prevent new hydrogen atoms from reaching the metal to react. When the temperature is raised to the base material's target range, above normal operating temperatures, the hydride surface layers dissolve and crack, which enables future hydrides to be formed. During this "recharging" process, the generated gasses, resulting from the hydride surface layers, are removed in an endothermic reaction. Titanium getters can be operated at $200-300^{\circ} \mathrm{C}$ and can be "recharged" at $500-700^{\circ} \mathrm{C} .{ }^{14,18}$ Titanium getters are of particular interest because of their use in various reactor tritium removal systems. The FSV reactor used titanium getters for hydrogen removal, which was problematic from an operational standpoint. ${ }^{5}$ 


\section{EFFECTS OF HELIUM IMPURITIES ON PRIMARY CIRCUIT MATERIALS}

The NGNP is being designed for a 60 -year service life; therefore, the selection of primary system component materials must carefully consider environmental degradation. No environment is inert with respect to the alloys being considered and the design parameters of expected use in the NGNP primary coolant system. The rate of degradation for any material depends primarily dependent on temperature and the impurity levels in the helium coolant. The environmental effects on the materials under consideration for the NGNP are addressed below.

\subsection{Reactor Design Suppliers' Material Considerations for NGNP Components}

The Reactor Design suppliers, General Atomics (GA), Westinghouse, and AREVA, have developed conceptual designs for the NGNP and have started making material selection for various components. The Reactor Design suppliers are evaluating the specific material considerations for key components in the primary circuit of the NGNP, which are control rods and related equipment, reactor pressure vessel, cross vessel, and the steam generator. These materials are included in this section to identify the materials that may be included in the primary circuit that could impact the helium chemistry for the primary circuit. INL's report, NGNP Materials White Paper, discusses in greater detail the suppliers' conceptual design plans for various NGNP components. ${ }^{19}$

Ideally, GA is considering several materials for the control rods and related equipment. Currently they are considering the use of ceramic materials for the control rods, carbon fiber-reinforced carbon matrix composite or a silicon carbide fiber-reinforced silicon carbide-matrix. This material selection is due to the very high fluence and temperatures that the materials will be exposed to during normal and offnormal conditions. However, a more readily available material option is being considered: Hastelloy X. Under normal operating conditions, the temperatures that the inner control rods can see temperatures in the range of 700 to $894^{\circ} \mathrm{C}$. Outer control rods can be exposed to temperatures between 420 and $526^{\circ} \mathrm{C}$. The guide tubes will be made of Hastelloy X. It is anticipated that the guide tubes will be exposed to temperatures between 340 and $930^{\circ} \mathrm{C}^{20}$ AREVA is considering several materials, as well; Incoloy $800 \mathrm{H}$, carbon fiber-reinforced carbon matrix composite, and silicon carbide fiber-reinforced silicon carbidematrix $^{21}$ are being considered for the control rod cladding, end caps, and articulating connections will be made of.

The reactor cross vessel is composed of two concentric cylinders that connect the reactor pressure vessel and the steam generator. The inner cylinder transports helium at $750^{\circ} \mathrm{C}$ from the reactor to the steam generator, and the outer cylinder delivers helium to the reactor inlet at around $350^{\circ} \mathrm{C}$. For the lower reactor outlet temperature, the reactor design suppliers are evaluating the use of Incoloy $800 \mathrm{H}$ as the cross-vessel liner, which is in direct contact with the high-temperature helium, and the use of SA508/533B as the inner-pressure piping material. The inner-pressure pipe is the inner-most material for the cooler helium flow to the reactor inlet. The three suppliers are looking at different solutions for the cross-vessel problem, and at the release date of this report, no official selection has been made on the design specifications for the cross vessel.

The design change that reduced the reactor outlet temperature to $750^{\circ} \mathrm{C}$ has caused the three reactor design suppliers to shift their interest from more exotic materials and RPV cooling systems to more conventional material options. The reactor design suppliers have chosen to use SA 508/533B steel for the NGNP RPV material, which has been used for LWR RPVs. The reactor design suppliers are planning to use the reactor inlet helium to cool the internal walls of the reactor vessel by directing the inlet coolant along the walls of the reactor vessel to maintain the pressure vessel material below the allowable normal 
operating temperature of $370^{\circ} \mathrm{C}$. These design considerations for the RPV are based on the ASME B\&PV code case N-499-2, which is discussed in greater detail in NGNP Materials White Pape. ${ }^{19}$

GA is evaluating the MHTGR SG design, which is a helical coil single once-through unit. Hot helium is passed over a bundle of helically coiled steam tubes. The upper section of the steam tubes, which is the superheated section, is made of Incoloy $800 \mathrm{H}$, and the lower of the two heat transfer sections is the evaporator-economizer section, which is made of $2 \frac{1 / 4}{\mathrm{Cr}}-1 \mathrm{Mo}$ steel. ${ }^{22}$ A very similar design using the same materials is being considered by AREVA. ${ }^{21}$ Westinghouse has considered several designs for the SG including, but not limited to, a helical coil shell and tube and a serpentine tube heat exchanger. ${ }^{23}$ While several other materials are being considered for use in the SG, the aforementioned materials have been formally declared to be of particular interest to the suppliers.

\subsection{Environmental Influences on Metallic Materials for the NGNP}

The overarching goal of this section is to take the metallic material that are likely candidates for use in the primary circuit of the NGNP and identify chemistry guidelines and identify other relevant parameters that could be used to develop and maintain the protective oxide layer, thereby increasing the life of reactor components. Initially the NGNP was conceptualized as operating with a reactor outlet temperature of $950^{\circ} \mathrm{C}$, but the technical challenges associated with material limitations and a 60 -year plant life resulted in a reduced outlet temperature of $750^{\circ} \mathrm{C}$. When this change occurred, there was a shift in material selection from more exotic materials to materials that are approved for use by the ASME in the needed temperature and pressure ranges. Materials like Inconel 617 and Haynes 230 were no longer prime choices; materials that were more familiar to industry became the materials of interest: SA 508/533B, 2-1/4 Cr - $1 \mathrm{Mo}$, and Incoloy $800 \mathrm{H}$. Reducing the reactor outlet temperature allowed SA 508/533B to be considered for use as the RPV material without the use of auxiliary cooling systems. It also enabled the use of $2-1 / 4 \mathrm{Cr}-1 \mathrm{Mo}$ and Incoloy $800 \mathrm{H}$ in SGs.

Three types of metals are being evaluated for use in the NGNP, and they can be broken down into low-alloy steel and high- and low-chromium materials. The low-alloy steels have a specific microstructure that determines their mechanical properties. Various heat treatments are used to develop a microstructure that is specially suited to the desired task. SA 508/533 are low-alloy steels that have the following applications: SA-508 Grade 3 Class 1 material is used for forgings, and SA-533 Type B Class 1 is used for plate. These materials have good mechanical properties, good aging resistance, and are tough. This material has been used for many years in LWRs and with the decreased reactor outlet temperatures of $750^{\circ} \mathrm{C}$, these materials are again applicable for reactor pressure vessels for HTGRs. Some modifications to the material compositions have resulted in tougher material and reduced sensitivity to thermal aging by reducing sulfur and phosphorus in the material composition. ${ }^{24} \mathrm{SA}-508$ is approved for use up to $370^{\circ} \mathrm{C}$ under the ASME B\&PV code for Class 1 nuclear components. Based on an extensive literature review, a minimal amount of data is available on these two materials regarding corrosion in high-temperature helium environments. At the lower operating temperature of the NGNP, it is expected that these materials will have limited corrosion, if any.

High- and low-chromium materials have virtually the same mechanism-to form a protective chromium oxide layer - to sustain their mechanical properties at high temperatures. The heat-resistant metallic materials planned for use in the NGNP require this protective oxide layer to be continuous over the surface of the material and to be continuously maintained to prevent irreversible material degradation. The high chromium materials, around $20 \% \mathrm{Cr}$, have excess chromium to form oxide layers and some of these materials are Incoloy 800H, Hastelloy X/XR, Inconel 617, and Haynes 230. Inconel 617 and Haynes 230 are not being considered for wide use in the NGNP, given the lower reactor outlet temperature, but they could be used in later plants. For that reason, they will be included in the materials discussion. These high chromium metals form oxide layers by chromium being removed from the base metal and chemically bonding with oxygen-containing molecules to form a protective oxide scale. Other 
types of scales and various layers of scales are formed depending on the composition of the base metal. The oxidation process depends on the oxygen partial pressure of the environment and the reactivity of the metallic surface that contacts the corrosive environment. This process beneficially uses corrosion to form a protective barrier that limits the rate of corrosion and material degradation. Without this protective layer, the material properties would be permanently reduced in a short amount of time at elevated temperatures in the primary circuit of an HTGR. It is also possible that the oxide scale would not form due to environmental conditions, which will be discussed in subsequent sections. Additionally, it is possible that the oxide layer could begin spalling. These failures to grow and maintain a continuous oxide layer need to be considered.

The lack of a continuous oxide layer could be disastrous for structural materials at elevated temperatures; carburization or decarburization can occur more rapidly in the absence of an oxide layer. Carburization occurs when carbon atoms diffuse into the base metal due to vulnerabilities in the oxide layer that allow the carbon atoms to reach the base metal and diffuse into it. It has been postulated that a low ratio of carbon to water in the helium coolant are vital factors that can lead to a stable oxide layer. ${ }^{25}$ In decarburization, the carbon in the base metal moves toward the interface between the oxide layer and the base metal. A ratio of high carbon to hydrogen gas can lead to the formation of surface carbides carburization. ${ }^{25}$ Carburization and decarburization should be minimized as much as possible because they both have pejorative and permanent consequences on mechanical properties of these materials. The best way to minimize these effects is to control the impurity levels to facilitate the growth of a stable oxide layer and to prevent the development of strong carburizing or strong decarburizing environments.

Ni-Cr-Mo materials in the HTGR environment have a critical temperature that is the threshold for chemical stability between the oxide layer and the base metal. Above a critical temperature, the oxide layer and the carbon in the base metal can no longer co-exist and as a result, reactions take place that prompt the removal the oxide layer or the carbon in the base metal. This is called the microclimate reaction and it goes to completion, unless environmental parameters are changed. The way to stop the continuation of the microclimate reaction is to create an oxidizing environment by increasing the water and $\mathrm{CO}$ levels in the coolant. The onset of the microclimate reaction is rapid and results in the destruction of the oxide layer or the loss of carbon from the base metal.

The critical temperature can change with the concentration of various impurities in the helium coolant - specifically, the amount of CO. Quadakkers obtained a curve that shows the relationship between the critical temperature and the concentration or partial pressure of $\mathrm{CO}^{26,27}$ The simple relationship between the $\mathrm{CO}$ content and the critical temperature is that increasing the $\mathrm{CO}$ content will increase the critical temperature to a point. This is an important consideration when deciding on a chemistry composition for a system that operates around the critical temperature of $900-970^{\circ} \mathrm{C} .{ }^{27}$ When the carbon concentration of the coolant enters a region of carburization or decarburization, the protective oxide layer can be destroyed. At the critical temperature, there is a CO partial pressure where too little or too much will result in rapid carburization or decarburization. It was postulated that at the critical point, the $\mathrm{CO}$ becomes somewhat more stable than the metal oxide and the metal carbide being formed.

The concentration of carbon impurities is extremely important to prevent carburization and decarburization, and both corrosion mechanisms reduce the effectiveness of the base materials, as previously discussed. Changes in technology should help reduce some varieties of the carbon molecules, which, in theory, could render the system more controllable. The large helium circulators have historically used oil- or water-lubricated bearings, which have introduced impurities into the primary circuit. The modern solution to this problem is to use electromagnetic bearings that do not require a lubricant. These bearings are being strongly considered by reactor design suppliers. The use of these bearings will reduce oil contaminants and consequently reduce the $\mathrm{CH}_{4}$. Another system change that may influence helium chemistry is the higher reactor outlet temperatures, which could result in lower concentrations of $\mathrm{CO}_{2}$ but potentially higher $\mathrm{CO}$ concentrations in some nuclear power plants. ${ }^{26,27,28}$ 
The key to maintaining strong materials in the harsh high-temperature environment is to maintain the protective oxide layer, which can be formed and destroyed over and over again. This type of cycling can be detrimental to the life of the material because there is a finite amount of chromium in the base metal. ${ }^{42}$ Due to the chromium depletion from the base metal to form a chromium-oxide layer on the surface of the base metal, a chromium-depleted region exists below the chromium-oxide layer. At the interface between the oxide layer and the metallic surface, the oxygen partial pressure is reduced due to the oxide layer preventing oxygen from readily reaching the metallic surface. During this low-oxygen partial pressure phase, even small amounts of oxygen can oxidize with manganese, silicon, titanium, and aluminum. These elements migrate toward the oxide and metallic interface. While these elements oxidize and become depleted in this region, chromium diffuses through the base metal from regions of higher chromium concentrations. As the material ages in the corrosive environment, the protective oxidizing materials are removed out of the base metal, leaving it less capable of forming an adequate protective scale. Additionally, manganese can become depleted in the base metal but enriched on the outermost region of the oxide layer. It was later determined that manganese can easily diffuse through the base metal and the outer oxide layer. Silicon can diffuse through the oxide layer, but at a slower rate than manganese. Aluminum has been shown to concentrate at the interface between the oxide layer and the base metal due to its low permeation rate. These high-chromium materials (Incoloy $800 \mathrm{H}$, Hastelloy X/XR, Inconel 617, and Haynes 230) are protected by the oxide layers that are influenced by minor alloying elements in the base metal. Finally, when significant diffusion occurs in the base metal, voids are created, which further reduces the mechanical properties of the base metal.

Incoloy $800 \mathrm{H}$ has a stable austenitic structure and is intended for use at temperatures above $593^{\circ} \mathrm{C}$ and is approved for use up to $761^{\circ} \mathrm{C}$ by the American Society of Mechanical Engineers (ASME). While there is substantial experience in the nuclear industry with this material, it is not approved for use in the ASME B\&PV code at higher temperatures because additional materials data is needed. ${ }^{19}$ Often, Hastelloy $\mathrm{X}$ and Incoloy $800 \mathrm{H}$ are used to perform similar jobs. Hastelloy $\mathrm{X}$ has a greater resistance to radiationinduced embrittlement.

Hastelloy $\mathrm{X}$ is a nickel-chromium-based alloy that has good resistance to oxidation up to $1200^{\circ} \mathrm{C}$ and good strength properties at temperatures up to $870^{\circ} \mathrm{C}$. Hastelloy $\mathrm{X}$ is a single-phase austenitic alloy strengthened by chromium, molybdenum, and tungsten. Hastelloy XR has exceptional corrosion resistance, which is attributed to the formation of a two-layer scale: the outer layer is $\mathrm{MnCr}_{2} \mathrm{O}_{4}$ and the inner layer is $\mathrm{Cr}_{2} \mathrm{O}_{3}$. Hastelloy X exhibited better resistance to oxidation than Incoloy $800 \mathrm{H}$ and Inconel 617 at temperatures between 750 to $870^{\circ} \mathrm{C} .{ }^{25}$ In addition, Hastelloy XR showed improved resistance to intergranular attack and internal oxidation above Hastelloy $\mathrm{X}$.

Inconel 617 is an austenitic alloy with nickel-chromium with additions of $\mathrm{Co}$, Mo, and $\mathrm{Al}$. Inconel 617 has exceptional creep strength at temperatures above $870^{\circ} \mathrm{C}$ and has good cyclic oxidation and carburization resistance. ${ }^{25}$ This is a highly effective heat-resistant material with excellent mechanical properties, assuming that there are sufficient oxidizing species in the environment. A comparison of the strength of Inconel 617 in high-temperature air and helium environments showed that it performed better in the air environment than a pure helium environment. This was because an oxide layer did not form in the helium environment but was able to form in the corrosive air environment. Reduced creep properties resulted in Inconel 617 when there were reduced levels of $\mathrm{H}_{2} \mathrm{O}$. Inconel 617, along with Hastelloy X/XR, is often used in components that will be exposed to temperatures up to $900^{\circ} \mathrm{C}$.

$2-1 / 4 \mathrm{Cr}-1 \mathrm{Mo}$ is a low-alloy, low-chromium material that is often heat treated by tempering to provide better mechanical properties. Tempering involves heating the material to $873-1023 \mathrm{~K}$ for 10 hours. This causes microstructural changes in the material that cause precipitation of Chromium carbides, such as $\mathrm{Cr}_{23} \mathrm{C}_{6}$ and $\mathrm{Cr}_{7} \mathrm{C}_{3}$ around the grain boundaries. ${ }^{29}$ This microstructure decreases the free chromium that would normally be used to form the protective $\mathrm{Cr}_{2} \mathrm{O}_{3}$ scale and therefore may not be able to form an adequate oxide barrier. This material can be used, but it must be operated in lower temperature 
environments, which has already been specified by material requirements. Substantial experience with this material in the fossil industry indicates that these difficulties can be circumvented by operating the RPV at low temperatures around $300-350^{\circ} \mathrm{C}$. In addition, $\mathrm{Fe}-2-1 / 4 \mathrm{Cr}-1 \mathrm{Mo}-0.25 \mathrm{~V}$ has increased material property benefits. The application of this material for the NGNP RPV would require additional research to determine the mechanical properties of the material for long-life operation, i.e., greater than 10,000 hours of operation.

$2-1 / 4 \mathrm{Cr}-1 \mathrm{Mo}$ has a substantial database for tensile, creep, fatigue, and creep fatigue properties. $2-1 / 4 \mathrm{Cr}-1 \mathrm{Mo}-\mathrm{V}$ is a modified version of Alloy $2-1 / 4 \mathrm{Cr}-1 \mathrm{Mo}$ that contains vanadium, niobium, nitrogen, and lower carbon content. This material is more resistant to thermal fatigue and lower thermal expansion than austenitic stainless steels. ${ }^{25}$ Another material, Grade 91 (9 $\left.\mathrm{Cr}-1 \mathrm{Mo}\right)$, has a lower thermal expansion, higher thermal conductivity, and improved oxidation resistance compared to $2-1 / 4 \mathrm{Cr}-1 \mathrm{Mo}$. Grade 91 is a material considered for RPV for the nth-of-a-kind (NOAK) plant at $950{ }^{\circ} \mathrm{C}$.

\subsection{Environmental Influences on Graphite for the NGNP}

The high-chromium alloys are a major concern regarding helium coolant, but equally important are the graphite structures within the core. The graphite core supports are susceptible to corrosion in the hightemperature HTGR helium environment, and these support structures are essential to the proper operation of the reactor. The graphite supports direct the helium coolant throughout the core, support the fuel assemblies, and moderate neutrons. If the graphite is degraded to a point that any one of these tasks is sufficiently impaired, the reactor would stop operating.

The NGNP graphite research and development $(R \& D)$ program is evaluating the graphite that has been selected by the reactor design suppliers to qualify them as nuclear-grade graphite. The R\&D program is focusing on: material property characterization, irradiated material property characterization, modeling, American Society for Testing and Materials (ASTM) test development, and ASME code development. ${ }^{30}$ An additional point of consideration is the available coke source for the given graphite types. The scarcity of a consistent coke source will make it difficult to produce large amounts of graphite with the same material properties. Using different coke sources will produce graphite with different material properties, which will make it necessary to qualify the new graphite before it can be used in nuclear applications. Several types of graphite are being evaluated to determine which ones will meet the design standards for nuclear applications; these are IG-430, NBG-17, NBG-18, PCEA, PGX, and 2020. The design standards for nuclear-grade graphite are broadly defined in the ASTM standard, ASTM D7219-08, Standard Specification for Isotropic and Near-isotropic Nuclear Graphites. ${ }^{31}$

Some of the testing for the NGNP is to determine the oxidation rates of the different graphites proposed for use in the core to determine the effect on graphite properties as well as the effect on the performance of the core. Additionally, due to regulatory requirements, thermal and mechanical properties testing of previously oxidized graphite will need to be performed to determine the effects of long-term oxidation exposure. ${ }^{32}$ In September 2007, there were no approved ASTM methods for measuring the oxidation rate of graphite, which is addressed by the NGNP graphite R\&D program.

Oxidation degrades the mechanical and thermal properties of graphite and therefore needs to be well understood to ensure the safety and maintainability of future nuclear power plants. Oxidation of graphite is greatly dependent on temperature. There are three distinct oxidation regimes that are separated by graphite temperature. At temperatures below $500^{\circ} \mathrm{C}$, oxidation occurs very slowly and uniformly throughout the core because the oxidizing gas penetrates deep into the graphite; this is called the chemical regime. Oxidation occurring at temperatures between $500-900^{\circ} \mathrm{C}$ is called the in-pore diffusion-controlled regime, which is a range of increasing oxidation that mainly oxidizes the graphite surface. At temperatures above $900^{\circ} \mathrm{C}$, the oxidation regime is the boundary-layer regime. At higher temperatures, as in the in-pore diffusion-controlled regime and the oxidation regime, the oxidation occurs 
at the surface of the graphite due to the high chemical reactivity of the hot graphite. Oxidation rate is controlled by the chemical reactivity of the graphite, which is a function of temperature. ${ }^{28}$ At these higher temperatures ranges, the surface geometry of the graphite can rapidly change without damaging the material in the interior. In addition, metallic impurities in graphite can act as catalysts by reducing the activation energy of the chemical reaction and increasing oxidation. This effect is more clearly seen at lower temperatures. ${ }^{24}$

The oxidation rate of graphite depends on temperature and the oxygen content of the environment. Based on these two factors, it becomes clear that maintaining low levels of water and other oxygen-containing impurities is essential for maintaining the integrity of the graphite structures in the primary circuit of the NGNP. 


\section{CHEMISTRY CONTROL FOR THE NGNP}

The helium purification system required for the NGNP is in place to protect components in the primary circuit from excessive corrosion and to reduce radioactive impurities. The NGNP's mission is to demonstrate that an HTGR can provide process heat to industrial applications in addition to producing electricity. Coupling an NGNP to an industrial application will require tight controls to prevent undesirable emissions from being transported to the industrial application. Two main mechanisms will help maintain low levels of impurities in the primary circuit and in subsequent processes: the HPS and the graphite core. The HPS is an active system that removes impurities, while the graphite core is a passive system that achieves a dynamic balance with impurities that gravitates toward a low steady-state impurity level while temporarily containing the excess impurities. The reactor impurities can be classified into two types: radioactive and non-radioactive. The radioactive impurities are expected to be relatively low due to the TRISO fuel particles that are designed to contain the fission products. It is anticipated that some fission products will be released from the fuel as well as activation products from internal materials. The non-radioactive impurities are present in the primary loop due to leaks, chemical reactions, impurities found in graphite, impurities found on and in fuel, and residual impurities present after startup.

\subsection{Radioactive Impurities}

Most of the radioactive impurities released by the tri-structural isotropic (TRISO) fuel are expected to be noble gases, while other radioactive gases, such as tritium, have various generation pathways. The noble gases plate out in the cooler regions of the core, which has been an effective control method in previous HTGRs. One of the most tightly controlled radioactive impurities targeted for removal in the primary coolant is tritium. Tritium is generated in significant quantities in the core from various sources. It is difficult to contain and poses a biological health risk when ingested. Given the NGNP's mission, it is extremely important that tritium is not transferred to downstream process heat applications in significant quantities.

The five dominant tritium-generation pathways in HTGRs are ternary fission and neutron absorption in lithium-6, lithium-7, boron-10, and helium-3. Ternary fission is expected to be the greatest source of tritium generation in the NGNP. The NGNP fuel will consist of TRISO fuel particles designed to contain fission products by using multiple containment barriers. TRISO fuel particles have been demonstrated to be effective at retaining fission products generated, including tritium. ${ }^{33}$

Lithium-6 isotopes are impurities found in small quantities in nuclear-grade graphite, but due to the large amount of graphite used in the core, thermal neutron absorption in lithium- 6 is likely, which results in significant tritium generation. The second greatest source of tritium generation in the HTGR is expected to be helium-3 absorption of thermal neutrons. Helium-3 is found in purified helium in significant quantities. Boron-10 is used in nuclear reactors as a neutron poison, which absorbs neutrons and prevents them from being available to induce fission. Boron-10 has two pathways to the generation of tritium, depending on whether one or two neutrons are absorbed. The second reaction actually involves the absorption of two thermal neutrons, which results in an intermediate generation of lithium-7.

Tritium is removed in very much the same way in all gas-cooled reactors, and it is anticipated that the NGNP will use the same methods used in previous HTGRs. Tritium can exist in several forms; to be brief, it can be in any of the following forms and more: T, TH, T2, HTO, TTO, and in various hydrocarbon molecules. The HPS first sends the helium coolant through an oxidizer, which converts hydrogen gas into water and other things. The next step is to capture the water on a molecular sieve. Trapped on the molecular sieve are various impurities, including tritiated water. Tritium is preferred in this form because it is more easily contained than in gaseous form. Tritium's permeability is 1000 times 
that of tritiated water. ${ }^{17}$ Gaseous tritium has a permeability of $1 /$ sqrt(3), which is smaller than deuterium, which has a permeability of $1 / \operatorname{sqrt}(2) .{ }^{14}$

While the HPS does specifically target tritium for removal, it will actually play a rather small role in the large-scale removal of the tritium contamination in the primary circuit. Hydrogen/tritium and other impurities can be continuously removed from the coolant by chemisorption in the graphite core. The graphite core establishes a dynamic quasi-equilibrium that maintains low levels of tritium in the coolant while containing the excess tritium. The amount of impurities that can be adsorbed is inversely proportional to temperature of the core and directly proportional to the concentration or pressure of the impurities in the gas phase. ${ }^{34}$ Out gassing occurs during moisture ingresses, power outages, and reactor power increases, which corresponds to temperature increases. A tritium study was performed at the Arbeitsgemeinschaft Versuchsreaktor (AVR) in Germany that clearly shows that the graphite is a sink for various impurities. A given amount of tritium was injected into the AVR and allowed to run for many hours. After a several hours the tritium levels in the core were much lower than anticipated, and upon checking the HPS for the amount of tritium removed from the core, the experimenters learned that the HPS removed only a small fraction of tritium. This experiment showed the adsorptive capabilities of the graphite core. Despite the HPS and the chemisorptions properties of the graphite core, tritium will still be present in the primary coolant and it is expected that tritium will be transported to the secondary circuit. As previously mentioned, the secondary circuit will very likely be coupled to a heat-transport application, which will require additional planning to further reduce tritium levels. It is possible that the tritium levels for the heat transport applications will have lower requirements than the regulator.

Nine high-temperature heat transport applications have been determined to be developed technologies that could use the process heat produced by an HTGR, and they are: hydrogen production, ammonia production from natural gas, ammonia production from coal, natural gas to liquids, coal to liquids, coal to gasoline, coal to substitute natural gas, and steam-assisted gravity drainage. ${ }^{24}$ Each of these products produced by transporting heat to industrial applications from an HTGR will be required to meet strict quality control concerns that protect the consumer. The following processes are used to produce energy sources and would be stored in large containers, eventually burnt, and contaminants released into the atmosphere: natural gas to liquids, coal to liquids, coal to gasoline, and coal to substitute natural gas. Releasing the byproducts of these fuels, which would be used in great quantities, could result in the distribution of radioactive contamination.

Tritium is introduced into the secondary circuit due to the tritium concentration gradient between the primary and secondary circuits. Tritium will diffuse through the SG boundary to the circuit that has a lower tritium concentration. There are plans to put barriers in place to limit the diffusion of tritium, but it is expected that, even under the best circumstances, tritium will permeate through the SG boundaries. It is possible to remove significant quantities of tritium from the secondary circuit while simultaneously operating the HPS in the primary circuit. This strategy is employed in the HTTR. The initial drawback to this decision is the secondary side of the NGNP is a steam/water cycle. It is expected that tritium removal from water will be more technically challenging because of the limited experience with this process on an industrial scale. There are methods available for tritium removal in the secondary circuit, which will be reviewed at a high level, mainly to inform that research is ongoing in this area. Many processes have been used to separate and enrich tritiated water from water. ${ }^{35,36,37,38}$

Many methods can be used to separate tritiated water: isotope exchange columns, $\mathrm{H}_{2} \mathrm{O} / \mathrm{HTO}$ distillation, electrolysis and cryogenic distillation, combined electrolysis and catalytic exchange, and catalytic exchange and cryogenic distillation. The catalytic exchange and cryogenic distillation method has been determined to be more cost effective, but other processes have distinct advantages, as well. These processes are specifically designed to operate in large, independent facilities. Temperatures and pressures for a majority of the purification processes are below $100^{\circ} \mathrm{C}$ and operate at several hundred $\mathrm{kPa}^{36,37,38}$ Some processes have been identified as having the capacity to process waste with a 
concentration of $47 \%$ heavy hydrogen and an activity of $10^{8} \mathrm{~Bq} / \mathrm{kg} .{ }^{37}$ Often, these systems use a standard for successfully purifying tritiated water by achieving a detritiation factor of $10^{3}$. Other systems have lower detritiation factors. For example, the tritium removal facility at the Wolsong CANDU6 reactor is expected to have a detritiation factor of 35 and operate at a capacity of $100 \mathrm{~kg} / \mathrm{h}$. This system is expected to remove $7 \mathrm{MCi}$ of tritium per year. ${ }^{39}$

Reducing the contamination in the secondary circuit may have substantial benefits by reducing hazards associated with leaks, maintenance, and downstream emissions, so inclusion of a tritium removal system in the secondary circuit should be strongly considered based on the plans to use HTGRs for process heat applications. Such a tritium removal system could be operated continuously or on a periodic basis to maintain tritium concentrations below a reasonable established value.

\subsection{Non-Radioactive Impurities}

Non-radioactive impurities present in the primary coolant are due to containment leaks, chemical reactions, impurities released from graphite during heat up, impurities found on and in fuel, and residual impurities present after startup. These impurities are often high during startup and after maintenance shutdowns, but the impurity levels fall to parts-per-million levels in the coolant rapidly due to the HPS and the large graphite core that heats up and adsorbs impurities. The high levels of impurities initially present are because the pressure in the piping in HTGRs is maintained at sub-atmospheric pressure to comply with regulatory requirements, which facilitates some air ingress. Impurities data from other HTGRs is available.

Some impurity levels of previous HTGRs, at steady-state operation, are provided in Table 2. Two HTGRs in the table have been designed but not built (GT-MHR and the PBMR), and their estimated impurity levels for normal operation have been provided. The bulk materials used in the primary circuit define the chemistry requirements, which are chosen to optimize the life of all major components in the primary circuit. As discussed in Section 3 of this report, high-chromium alloys and graphite are the two main types of material that, at least in part, drive the primary helium chemistry requirements for the NGNP. Due to the large quantity of graphite used in helium-cooled, graphite-moderated reactors, it is reasonable to reduce the amount of moisture in the core to reduce the oxidation of the graphite.

Table 2. Table of helium chemistry for gas reactors.

\begin{tabular}{|c|c|c|c|c|c|c|c|}
\hline & \multicolumn{7}{|c|}{ Impurity Levels at Steady-state Operation (ppm) } \\
\hline Plant & $\mathbf{H}_{2} \mathbf{O}$ & $\mathbf{H}_{2}$ & $\mathrm{CO}$ & $\mathrm{CO}_{2}$ & $\mathrm{CH}_{4}$ & $\mathbf{N}_{2}$ & $\mathbf{O}_{2}$ \\
\hline GT-MHR & 2 & - & $\mathrm{CO}+\mathrm{C}$ & & - & - & - \\
\hline Peach Bottom ${ }^{5}$ & 0.5 & 10 & 0.5 & $<0.5$ & 1 & 0.5 & - \\
\hline Fort St Vrain ${ }^{5}$ & 1 & 7 & 3 & 1 & 0.1 & - & 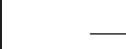 \\
\hline $\mathrm{AVR}^{5}$ & 0.15 & 9 & 45 & 0.25 & 1 & 22 & - \\
\hline HTTR (upper limit) ${ }^{40}$ & 0.2 & 3 & 3 & 0.6 & 0.5 & 0.2 & 0.04 \\
\hline HTR- $10^{8}$ & $</=1$ & $</=9$ & $</=9$ & $</=1$ & $</=3$ & $</=2$ & 1 \\
\hline $\mathrm{PBMR}^{41}$ & $<0.2$ & $2-11$ & $2-11$ & $<0.2$ & $<0.1$ & $3-115$ & 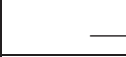 \\
\hline Dragon $^{34}$ & $0.05-0.1$ & $0.8-2.0$ & $0.5-1.0$ & $<0.02$ & 0.15 & 0.15 & - \\
\hline THTR & $<0.01$ & 0.8 & 0.4 & 0.2 & 0.1 & 0.1 & - \\
\hline
\end{tabular}


The impurity levels shown in Table 2 have similar values. The $\mathrm{H}_{2} \mathrm{O}$ impurity levels range from $0.01 \mathrm{ppm}$ to $2 \mathrm{ppm}$; all values but one are $1 \mathrm{ppm}$ or less. The hydrogen levels range from $0.8 \mathrm{ppm}$ to $10 \mathrm{ppm}$ in Table 2. Hydrogen can be produced in various ways in the core, such as during oxidation of various metals during the decomposition of methane and the oxidization of graphite. Also, hydrogen is readily produced when water is present in the primary circuit. The CO levels provided in Table 2 range from $0.4 \mathrm{ppm}$ to $45 \mathrm{ppm}$. The higher operating temperatures of the HTGR promote the development of $\mathrm{CO}$ more than $\mathrm{CO}_{2}$. It is expected that by controlling the water impurity levels, there would be lower levels of $\mathrm{CO}$ being generated. The $\mathrm{CO}$ levels are important at higher temperatures around $900^{\circ} \mathrm{C}$ because the concentration of $\mathrm{CO}$ directly influences the stability of the oxide layer on most metallic materials in the core, specifically the high-chromium, nickel alloys. $\mathrm{CO}_{2}$ levels range from $<0.02 \mathrm{ppm}$ to $\sim 1 \mathrm{ppm}$. In the AVR it was determined that there were no constant ratios of $\mathrm{CO} / \mathrm{CO}_{2}$ over long periods of time. A relationship between $\mathrm{CO}$ and $\mathrm{CO}_{2}$ was determined based on temperature. It appears that increasing temperatures favor an increase in $\mathrm{CO}$ levels. ${ }^{43} \mathrm{The}^{\mathrm{CH}} \mathrm{H}_{4}$ levels are expected to be considerably lower as well. The elevated operating temperatures of the HTGR are expected to destabilize $\mathrm{CH}_{4}$ and promote more hydrogen production. Additionally, the $\mathrm{CH}_{4}$ levels were influenced by lubricants introduced into the primary circuit by bearings in the large helium circulators. These bearings will most likely be replaced with lubricant-free electromagnetic bearings, thereby reducing the levels of $\mathrm{CH}_{4}$. In addition to being created by oil ingress, methane is produced in HTGRs by radiolytic reactions. A relationship has been determined to exist between $\mathrm{CH}_{4}$ and $\mathrm{H}_{2}$. The $\mathrm{CH}_{4}$ concentrations have seen to increase with increasing $\mathrm{H}_{2}$ amounts, up to a point where the relationship breaks down. ${ }^{44}$ Hydrogen levels are expected to influence the methane concentrations to a small degree. The levels of $\mathrm{CH}_{4}$, shown in Table 2, range from $0.1 \mathrm{ppm}$ to less than or equal to $3 \mathrm{ppm}$. The ranges for $\mathrm{N}_{2}$, also from Table 2 , range from $0.1 \mathrm{ppm}$ to 115 ppm. $\mathrm{N}_{2}$ has been determined to be minimally reactive in the HTGR environment and is not expected to have a major impact on the helium chemistry. Of course, best practices would require that nitrogen levels be kept low. $\mathrm{O}_{2}$ levels are expected to be nonexistent due to the high level of chemical reactivity at the operating temperature of the HTGR.

In Table 3, values for the NGNP HPS have been estimated based on previous operating experience and materials studies. Oxygen is very reactive at elevated temperatures and it is expected that it will not exist in gaseous form in the core at elevated temperatures. The water content of the primary circuit is extremely important to the formation of the protective oxide layer for metallic structures. The amount of water should be maintained at low concentrations to protect the graphite in the core from oxidization, but should be sufficiently high as to form a continuous oxide layer on the nickel-chromium-molybdenum (Ni$\mathrm{Cr}-\mathrm{Mo}$ ) materials in the primary circuit. The actual amount of $\mathrm{H}_{2} \mathrm{O}$ that is needed to oxidize a Ni-Cr-Mo metallic surface at the normal operating temperatures is quite low and $\mathrm{CO}$ also aids in the oxidization of these materials. If the concentration of $\mathrm{H}_{2} \mathrm{O}$ is too low, then an insufficient oxide layer will be formed that will lead to the excessive corrosion of internal metallic structures. An insufficient layer of oxide would be an incomplete layer that leaves the material surface exposed and susceptible to high temperature corrosion. If the $\mathrm{H}_{2} \mathrm{O}$ concentration is too high, the hot graphite core will begin to exothermically oxidize the contacting surfaces between the $\mathrm{H}_{2} \mathrm{O}$ and the graphite. At the lower operating temperatures, less water is required to oxidize the metallic surfaces in the primary circuit. With the lower reactor outlet temperature of $750^{\circ} \mathrm{C}$, smaller amounts of water are needed. It is also important to consider that the greater the concentrations of water, the thicker the oxide layer. Based on these factors, $1 \mathrm{ppm}$ to $2 \mathrm{ppm}$ of $\mathrm{H}_{2} \mathrm{O}$ has been chosen as the ideal concentration for the NGNP chemistry.

The CO content of the NGNP helium coolant is based on the effects that CO have on the base metals in the primary circuit at normal operating temperatures. Based on this, a small amount of $\mathrm{CO}$ could be maintained in the primary circuit. The CO can also be used to build the protective oxide layer, but to a much lesser extent than $\mathrm{H}_{2} \mathrm{O}$. The $\mathrm{CO}$ content becomes more important at elevated temperatures around $900-970^{\circ} \mathrm{C}$. The greater the $\mathrm{CO}$ content, the higher the critical temperature, up to a point. With modest moisture content, a higher $\mathrm{CO}$ content would provide some oxygen for the formation of an oxide layer, 
while also provide additional $\mathrm{CO}$ content that would cause the critical temperature to be pushed higher. Pushing the critical temperature higher helps protects the environment from reaching a carburizing or decarburizing condition. The estimated value of CO in the NGNP was chosen to range between $2 \mathrm{ppm}$ and $4 \mathrm{ppm}$. This value would be higher if the reactor outlet temperature would be higher.

The $\mathrm{H}_{2}$ content of the helium coolant is pretty variable based on the operating experience. There are several reactions that are expected to generate hydrogen gas, which often involve the decomposition of $\mathrm{H}_{2} \mathrm{O}$ and $\mathrm{CH}_{4}$. The graphite core will bond and hold a significant percentage of the total $\mathrm{H}_{2}$. It is expected that the $\mathrm{H}_{2}$ content will be in the range of $2 \mathrm{ppm}$ to $10 \mathrm{ppm}$, which is based on the operational experience provided in Table 2. Due to the high amount of high-chromium content metals that are expected to be used in the primary circuit, it is expected that a significant amount of $\mathrm{H}_{2}$ could be produced.

The $\mathrm{CO}_{2}$ content of the NGNP is expected to be relatively low. The $\mathrm{CO}_{2}$ content of the helium coolant is not expected to dramatically influence the coolant chemistry balance. In previous plants, the $\mathrm{CO}_{2}$ concentration has been relatively low, usually staying below $1 \mathrm{ppm}$, as shown in Table 2 . The range of the $\mathrm{CO}_{2}$ is suggested to be around $0.1 \mathrm{ppm}$ to $1 \mathrm{ppm}$, which is shown in Table 3.

Table 3. Approximated Helium Chemistry for HTGR

\begin{tabular}{|c|c|c|c|c|c|c|}
\hline $\mathbf{H}_{2} \mathbf{O}$ & $\mathbf{H}_{2}$ & $\mathbf{C O}$ & $\mathbf{C O}_{2}$ & $\mathbf{C H}_{4}$ & $\mathbf{N}_{2}$ & $\mathbf{O}_{2}$ \\
\hline $1-2 \mathrm{ppm}$ & $2-10 \mathrm{ppm}$ & $2-4 \mathrm{ppm}$ & $0.1-1 \mathrm{ppm}$ & $0.1-1 \mathrm{ppm}$ & $0.1-2 \mathrm{ppm}$ & - \\
\hline
\end{tabular}

The concentration of $\mathrm{N}_{2}$ in the primary circuit is expected to be relatively small due to the expected leak tightness of the NGNP, which is assumed to be better than previous HTGR because of the experience with FSV. The levels of $\mathrm{N}_{2}$ are relatively unimportant, but the levels of $\mathrm{N}_{2}$ will be controlled. It is expected that there will be a substantial amount of $\mathrm{N}_{2}$ in the primary circuit at startup, but it is expected that the impurity levels will fall with increasing temperature of the core.

The range of the total impurities, shown in Table 3, range from $5.3 \mathrm{ppm}$ to $20 \mathrm{ppm}$. This is a substantial range of possible chemistries, but the range is intentionally large. There are several important factors that have not been decided upon, which will impact the coolant chemistry. The amount and type of metals used throughout the primary circuit and an assessment of what the graphite is expected to do. To properly assess the chemistry for the NGNP, more needs to be known about the graphite and how it will react with the HTGR coolant.

The objective of this study is to determine chemistry requirements for the helium coolant that can produce an oxide layer that minimizes carburization and decarburization, while minimizing the unavoidable oxidation of the core graphite. Additionally, at elevated temperatures, around $900^{\circ} \mathrm{C}$, the concentration of $\mathrm{CO}$ strongly influences the microclimate reaction, which can lead to the onset of carburization or decarburization. At the lower reactor outlet temperature of $750^{\circ} \mathrm{C}$, this is not expected to be a problem during normal operation. The size of the HPS will ultimately depend on the helium chemistry requirements, which are based on, in part, the operating temperatures, and the structural materials used in the primary circuit. ${ }^{34}$ 


\section{APPROACH TO CHEMISTRY CONTROL FOR THE NGNP}

HPSs in HTGRs uses a small bypass stream that is siphoned off from the primary coolant stream and removes impurities from the bypass stream with oxidizers, low-temperature traps, and molecular sieves to filter impurities. Instruments are strategically placed around the primary circuit in locations where it is important to know the levels of impurities - places like the inlet and outlet of the reactor core, the outlet of the steam generator, and the outlet of helium circulators. The readings from these instruments are used to determine whether additional impurities need to be reintroduced to obtain a desired coolant mixture or determine if there is a leak in the primary circuit. It is expected that the helium coolant contains levels of $\mathrm{H}_{2}, \mathrm{CO}, \mathrm{CO}_{2}, \mathrm{CH}_{4}, \mathrm{H}_{2} \mathrm{O}$, and $\mathrm{N}_{2}$. The total impurity concentration in the helium coolant is expected to be less than 10 ppm. ${ }^{41}$ The HPS' main objective is to maintain a desired coolant chemistry, which involves adding and removing small amounts of several compounds to the helium coolant that preserves the metallic and graphite structures. To effectively maintain impurity levels within the primary circuit, the HPS needs to have a mass flow rate that can be accommodated by appropriately sized components designed for impurity removal.

The location of the primary taps that siphon coolant from the primary circuit can be selected to target locations in the circuit that may be more sensitive to impurities or in locations that ingress events are expected to start. Purified helium is reintroduced to the primary circuit, in part, by having it blown over seals to remove debris from various areas. The debris from these areas have small taps that siphon off small amounts of helium and stirred up debris that are sent for purification. Some of the small ports that remove helium are located in the inner cavity of the helium circulators and around mechanical seals. In HTGRs, the locations of large taps, or major bypass lines, which siphons off significant amounts of helium for purification in the HPS vary depending on the reactor design. In Table 4, four different reactors have been examined and the locations of their HPS siphon locations have been identified and presented.

Table 4. Table of HPS siphon locations for HTGRs.

\begin{tabular}{|l|l|}
\hline \multicolumn{1}{|c|}{ Reactor } & \multicolumn{1}{c|}{ Location of Helium Removal } \\
\hline HTTR & Auxiliary heat exchanger \\
\hline Peach Bottom & Reactor and SG \\
\hline FSV & Reactor inlet plenum \\
\hline GT-MHR & Outlet of high-pressure compressor \\
\hline
\end{tabular}

The main bypass line can draw helium from almost anywhere in the primary circuit, but some locations are more advantageous than others. The two siphoning locations of greatest promise for the NGNP, using the locations specified in Table 4, are in the reactor and in the SG. Siphoning helium from the reactor core would help continuously remove contaminants, which would be very helpful in the case of significant impurity ingress. It could also help remove a greater amount of impurities born in the core from the system before it gets distributed throughout the core. The other location of interest, the SG, is ideal for removing moisture ingress. It is possible that the SG will leak into the primary circuit and introduce impurities. Pulling a significant quantity of the bypass flow from this location could remove a significant amount of moisture in the event of a leak before it reaches other areas of the circuit. Both Peach Bottom and FSV siphoned off helium from the reactor core, and both helium purification systems have been highly effective. As a result of the successful operating experience of previously discussed HPSs, it is a prudent design consideration to develop a HPS that still siphons helium from the reactor core and or the SG. 
The HPS siphons off helium on the order of $1 \%$ to $15 \%$ of the total coolant flow in the primary circuit. FSV siphoned off $12 \%$ of its total flow, while the MHTGR was designed to remove much less than $1 \%$ of the total coolant in the primary circuit. FSV and the MHTGR are designed to purify 185,000 $\mathrm{kg} / \mathrm{h}$ and $386 \mathrm{~kg} / \mathrm{h}$ of their primary coolant, respectively. These HPSs are on much different scales, one accommodating a large flow rate through the HPS and the other have a considerably smaller capacity.

As with all things in engineering, there are tradeoffs. If a system is built to accommodate a large flow rate and operate efficiently, the system will be very large and expensive. On the other end of the spectrum, if the HPS is designed and built too small and it does its job ineffectively, operational difficulties may ensue, which may become more costly in the future. Decisions regarding the size of the HPS come down to meeting regulatory requirements and cost effectively designing and operating a HPS that at least meets the minimum purification requirements to achieve and maintain the desired impurity levels.

HTGRs are required to filter and store the entire capacity of the primary circuit in a 24-hour period. This would require roughly $4 \%$ of the total volume of the primary circuit to be filtered per hour. The HPS does not need to run at maximum capacity all the time, which establishes the possibility for variability in the operation of the HPS. The HPS needs to be operated at a capacity that limits the release of contaminants that are controlled, like tritium. The HPS is used to uphold worker safety standards in and around the plant, as well as help the plant meet emissions standards.

The level of desired impurities in the coolant is strongly related to the mass flow rate through the components in the HPS and the size of the components in the HPS. These two factors basically determine the residency time of the helium in components in the HPS that removes impurities. At excessively high flow rates, impurities would be less effectively removed because they would have less time to react with the bonding agents or achieve a sufficiently low temperature for removal, depending on the mechanisms of removal for each component. On the component level, the residency time of the helium in each component is a key factor to be considered when sizing each component and selecting a flow rate through the HPS. The required residency time for the individual components in a HPS is based on the time required to capture a given percentage of targeted impurities.

In addition to a dependable bypass stream, the HPS will also need to be properly instrumented to accurately measure the impurity levels around the loop. These sensors are placed in areas that have a greater potential for an ingress event and in areas that have high sensitivity to contamination. Two prime examples of these situations are the SG and the reactor core. The SG has a high probability of water ingress due to leaks and breaks. The reactor core is sensitive to moisture because moisture in the core can lead to increased moderation of neutrons and can cause an increase in reactivity above certain concentrations.

Several types of instruments are used to measure impurity levels in a reactor, but two types are essential to the proper operation of the HPS: the gas chromatograph and a moisture detector. The gas chromatograph can be used to accurately determine the impurity levels in the circulating helium because the impurity levels in the primary circuit are quasi steady state. Sensors are placed at the inlets and outlets of various components in the primary circuit to measure the difference in contamination levels once they have passed through the component of interest. The ranges for non-moisture-related impurities for HTGR range from 0.1 to $115 \mathrm{ppm}$, as shown in Non-radioactive impurities present in the primary coolant are due to containment leaks, chemical reactions, impurities released from graphite during heat up, impurities found on and in fuel, and residual impurities present after startup. These impurities are often high during startup and after maintenance shutdowns, but the impurity levels rapidly fall to the ppm levels due to the HPS and the large graphite core that heats up and adsorbs impurities. Graphite is porous and at startup, the graphite off-gases its contents, resulting in a short term increase in coolant impurities. The high levels 
of impurities after maintenance outages is due to the pressure in the HTGR piping being maintained at sub-atmospheric pressure to comply with regulatory requirements, which facilitates some air ingress.

Some impurity levels of previous HTGRs, at steady-state operation, are provided in Table 2. Two HTGRs in the table have been designed but not built (GT-MHR and the PBMR), and their estimated impurity levels for normal operation have been provided. The bulk materials used in the primary circuit define the chemistry requirements, which are chosen to optimize the life of all major components in the primary circuit. As discussed in Section 3 of this report, high-chromium alloys and graphite are the two main types of material that, at least in part, drive the helium chemistry requirements for the NGNP. Due to the large quantity of graphite used in helium-cooled, graphite-moderated reactors, it is reasonable to reduce the amount of water in the core to reduce the oxidation of the graphite.

Due to the wide range of impurities, an instrument that can detect several types of impurities over a wide range is ideal. It is expected that the impurity levels will be slow to change under normal operating experience. Three major scenarios could lead to significant changes in coolant chemistry; they are: air ingress, water ingress, and introducing new fuel into the reactor. The air ingress is likely to occur when the plant is offline, which is a result of Nuclear Regulatory Commission (NRC) requirements that require the plant to be maintained at subatmospheric pressures. Water ingress is more likely to occur during operation due to the thermal load as well as changes in the thermal load, i.e., startup and power increases. Introducing new fuel to the reactor can introduce impurities by contaminants on the surface of the fuel as well as impurities that are entrained in the outer graphite coating. It is expected that power changes in the core will result in changes to impurity concentrations. When temperatures return to previous levels, the impurity levels gravitate back toward the previously established impurity levels without interference from operators or the HPS. Due to the slow rate of change in impurity levels, the gas chromatograph can measure all relevant impurities.

The other essential instrument in the HPS is a moisture detector. This piece of equipment is necessary for plant safety and normal operation, and it is useful to the HPS. Moisture levels for some reactors have been specified in Non-radioactive impurities present in the primary coolant are due to containment leaks, chemical reactions, impurities released from graphite during heat up, impurities found on and in fuel, and residual impurities present after startup. These impurities are often high during startup and after maintenance shutdowns, but the impurity levels fall to ppm levels in the coolant rapidly due to the HPS and the large graphite core that heats up and adsorbs impurities. The high levels of impurities initially present are because the pressure in the piping in HTGRs is maintained at sub-atmospheric pressure to comply with regulatory requirements, which facilitates some air ingress. Impurities data from other HTGRs is available.

Some impurity levels of previous HTGRs, at steady-state operation, are provided in Table 2. Two HTGRs in the table have been designed but not built (GT-MHR and the PBMR), and their estimated impurity levels for normal operation have been provided. The bulk materials used in the primary circuit define the chemistry requirements, which are chosen to optimize the life of all major components in the primary circuit. As discussed in Section 3 of this report, high-chromium alloys and graphite are the two main types of material that drive the helium chemistry requirements for the NGNP. Due to the large quantity of graphite used in helium-cooled, graphite-moderated reactors, it is reasonable to reduce the amount of water in the core to reduce the oxidation of the graphite.

In Table 2, the values for water impurities in the helium coolant range from 0.01 to $2 \mathrm{ppm}$. These ranges of moisture indicate that sensitive moisture instrumentation is needed in order to accommodate the possible moisture range. Additionally, the moisture detectors will need to be able to rapidly notify operators in the event of a moisture ingress, usually within several seconds of an ingress. The rapid notification of a moisture ingress is essential to protect the core. Excessive moisture in the reactor core can result in an unscheduled increase in reactivity. Electrolytic, tunable diode lasers and dew-point hydrometers are reasonable choices for rapid-response moisture detectors. ${ }^{1}$ 
The coolant chemistry is monitored in several locations in the primary circuit by sensors and at manual extraction points, where coolant is removed from the circuit and tested in a laboratory. Samples are removed from the primary loop by a glovebox apparatus and transported in an aluminum bag to the necessary lab equipment and radioactive and non-radioactive impurities are measured. There are nine extraction ports in the small research reactor, HTTR that can accommodate this type of gas sampling. In power plants, these types of sampling ports are important for measuring gas impurities, but it is difficult to determine the number of sampling ports that would be required for a full size HTGR.

As previously discussed, impurities are removed by a bypass loop that siphons off a small amount of helium from the primary circuit, removes the impurities, and returns the coolant. The bypass loop ideally removes all of the targeted impurities. Some impurities, like iodine, will not get filtered out, but plateout on cooler surfaces in the primary circuit. The contaminants that are specifically targeted for removal in the HPS are $\mathrm{H}_{2}, \mathrm{CO}, \mathrm{CO}_{2}, \mathrm{CH}_{4}, \mathrm{H}_{2} \mathrm{O}$, and $\mathrm{N}_{2}$.

These impurities, in excessive concentrations, can lead to rapid corrosion, potentially destroying internal structures in the primary circuit. However, beneficial balances can be reached between some impurities that facilitate the growth of an oxide layer that protects the metallic structures. The most important balance has been determined to be between $\mathrm{CO} / \mathrm{H}_{2} \mathrm{O}$ and $\mathrm{CO} / \mathrm{H}_{2}$. In order to maintain the correct chemistry in the system, excessive impurities need to be filtered out and specific predetermined concentrations need to be reintroduced to maintain the necessary chemistry balance. The impurities are added as needed, which is based on several factors: the set point for the impurity levels, temperature, mass flow rate in the primary loop, and impurity levels currently in the primary circuit. The impurity levels in the primary circuit are a function of the mass flow rate through the HPS and the efficiency of the HPS, but the most important component of maintaining a chemistry balance is the graphite in the core. While the HPS does filter a significant portion of the coolant, the graphite acts as a large sump that collects and holds impurities until there is a parameter shift that causes the graphite to off-gas its contents. The HPS ideally removes all targeted impurities from the bypass loop, but the HPS also reintroduces impurities in sufficient amounts to balance the coolant chemistry in the loop. The HPS should also be able to allow for the depressurization of the primary loop within 24 hours following reactor shutdown. It will need to have a purification constant of greater than or equal to $2.9 \times 10^{-5}$ per second, which is the mass flow rate through the HPS divided by the total mass of the circulating helium.

The various sensors are used to inform the operators of ingress events and also to send information to the computer controlling the HPS. Depending on the impurity levels in the circuit, impurities are added to the circuit at the exit of the circulator in precise amounts. The reason for this location is to facilitate mixing after leaving the circulator. In theory, the chemistry right after the circulator should most closely resemble the ideal chemistry chosen by the reactor designers. At other parts in the primary loop, it is possible that impurities will chemically bond to internal structures. The possibility of an interaction and a chemical reaction increases with increasing reactive surface area, which increases with time. While this does increase the chances for slight differences in the coolant chemistries at opposite ends of the loop, the velocity of the coolant is relatively high. A high velocity suggests that the contaminants will remain fairly well distributed in the flow throughout the primary circuit. The goal of the HPS is to control the coolant chemistry and keep it within acceptable operating parameters.

The current approach used to control coolant chemistry in a nuclear power plant is to remove a small stream of helium from the main circuit and purify it using oxidizers, molecular sieves, and cold charcoal traps. The purified helium is then sent to the helium storage tanks, which are used to provide purified helium to the primary circuit when needed. The primary circuit uses gas chromatographs, sensors, and manual sampling to determine the concentrations of impurities in the helium, which dictate what impurities are injected into the circuit and the quantities of each. This system, coupled with the beneficial absorptive properties of the graphite core, will maintain the non-radioactive impurity levels below $10 \mathrm{ppm}$ during normal operation. ${ }^{41}$ 


\section{CONCLUSIONS AND RECOMMENDATIONS}

Based on an extensive literature review over the broad range of topics discussed in this report, there were several points from each section that are important to the understanding concepts that are directly applicable to coolant chemistry control in HTGRs. The main conclusions of the report are as follows:

- Several HTGR HPSs have been reviewed and the systems that have been reviewed are very similar and use the same basic strategy of siphoning off a small percentage of the total coolant in the primary circuit and purifying that smaller bypass flow.

- Impurities are maintained in the primary coolant of HTGRs to facilitate the development of a slow growing and continuous oxide layer that acts as a barrier to prevent excess corrosion in the form of carburization or decarburization.

- The oxide layer in the Cr-Ni-Mo metals becomes unstable at temperatures in the range $900-970{ }^{\circ} \mathrm{C}$. The instability temperature is called the critical temperature and designates the onset of a destabilization of the oxide layer and the carbon within the base metal. This reaction is called the microclimate reaction.

- The microclimate reaction results in the loss of either the oxide layer or the removal of the carbon in the base metal. The reaction goes to completion unless the initiating parameters are changed to an oxidizing environment again, by increasing $\mathrm{CO}$ and $\mathrm{H}_{2} \mathrm{O}$ concentration in the primary circuit.

- The carbon content of the helium environment influences the onset of the microclimate reaction. Increased amounts of $\mathrm{CO}$ cause the critical temperature to increase, thereby facilitating a higher operating temperature for the metallic structures before the occurrence of extensive material degradation.

- Graphite aggressively oxidizes at temperatures in the range of $500-900^{\circ} \mathrm{C}$ and as a result, the surfaces of the graphite structures are oxidized while the graphite internals are relatively untouched.

- Due to the highly reactive nature of graphite with oxygen at the expected operating temperatures, the concentration of water in the primary circuit needs to be balanced so that an adequate oxide layer can be formed, while limiting the amount of graphite oxidation.

- $\mathrm{H}_{2} \mathrm{O}$ and $\mathrm{CO}$ impurities have the greatest impact on the materials in the primary circuit.

- $\quad \mathrm{CO}$ oxidizes graphite to a much lesser extent than water, which needs to be considered when selecting the coolant chemistry. $\mathrm{CO}_{2}$ is not reactive until gamma radiation splits off an oxygen molecule, which is not uncommon in AGRs in Europe.

- The purification of the helium coolant is accomplished by two mechanisms: the HPS, which actively removes impurities and the graphite core that chemisorbs impurities. In HTGR, the graphite core and has historically maintained low impurity levels in the primary circuit. The volume of the graphite core makes it much more prominent in the control of the coolant chemistry, much more so than the HPS. The graphite core chemisorbs impurities and retains them until temperature changes trigger a release of impurities, which is called off-gassing.

Based on the information extracted from numerous sources, there are several recommendations about the HPS for the NGNP, which are provided below.

- The same methods have been consistently used to purify helium in HTGRs and the capabilities of the components their HPSs have been proven to be effective. It is recommended that the latest instrumentation be used to detect impurities, while using the same approach to remove impurities that has been used in HTGRs, thus far. The previous approaches withdrew a continuous stream of coolant from the primary circuit and passed the bypass stream through the oxidizers, molecular sieves, and low temperature charcoal beds. 
- The flow rate of the bypass stream has to accommodate the requirement that the HTGRs have to be able to be evacuate all the coolant in the primary circuit within a 24-hour period. This requires the HPS to be able to pump and purify slightly more than $4 \%$ of the total primary coolant per hour. The HPS isn't required to operate at that flow rate during normal operation. Based on the required evacuation flow rate and comparing the flow rates of previous reactors, it is recommended that the standard operating flow rate should meet or exceed $4 \%$ of the total primary coolant flow rate per hour. The helium coolant chemistry should resemble the following recipe, which is based on material corrosion data and previous operating experience. The recommended ranges of impurities in the coolant are: $1 \mathrm{ppm}-2$ ppm of $\mathrm{H}_{2} \mathrm{O}, 2 \mathrm{ppm}-10 \mathrm{ppm}$ of $\mathrm{H}_{2}, 2 \mathrm{ppm}-4 \mathrm{ppm}$ of $\mathrm{CO}, 0.1 \mathrm{ppm}-1 \mathrm{ppm}$ $\mathrm{CO}_{2}, 0.1 \mathrm{ppm}-1 \mathrm{ppm}$ of $\mathrm{CH}_{4}$, and $0.1 \mathrm{ppm}-2$ ppm of $\mathrm{N}_{2}$.

- The previous HTGR that were built and used in the United States were used for electrical power generation and therefore didn't require the use of a secondary side HPS. The HTTR was designed to deliver process heat to produce $\mathrm{H}_{2}$ by steam reforming of natural gas, which required the use of a HPS on the primary and secondary circuit to prevent the $\mathrm{H}_{2}$ product from becoming overly contaminated with tritium. The NGNP is being designed to produce electricity as well as deliver heat for process heat applications. It is recommended that there should be a HPS on the primary and secondary circuit of the NGNP to reduce tritium contamination of the heat application products. The secondary circuit of the NGNP will use water as the coolant, which will require tritium to be removed from the water coolant.

Additional work is recommended in the following areas.

- It will be beneficial to quantify the impact that the graphite core could have on the purity of the helium coolant. The various graphite types that are being considered for use in the NGNP and the graphites should be assessed to determine the amount of impurities that could be removed from the primary coolant. This type of information would help size the HPS as well as help more accurately set safety limits to protect the oxide layer on metallic structures within the primary circuit.

- It is necessary to try and optimize the coolant chemistry in the primary circuit to protect the mechanical properties of the various internal materials during various operating scenarios. This can be done by performing more tests varying the impurities for the various internal materials. Further work is needed to define the optimum coolant chemistry.

- It is necessary to determine the parameters that will be used in the coolant chemistry purification system for the water/steam secondary circuit of the NGNP. The stated goal of the NGNP is to provide energy for process heat applications, which will require the product to have low levels of radioactive contamination. To accomplish this, it has been recommended above that a secondary coolant chemistry loop would be designed and operated to remove tritium from the secondary circuit's water coolant. 


\section{REFERENCES}

1. PLN-3501, 2010, "Instrumentation Strategy for Test Loops and Facilities for the Heat Transportation Portion of NGNP," June 2010.

2. Burnette, R., and W. Bell, 1971, "Chemical Impurities in the Helium Coolant at the Peach Bottom HTGR,” GULF-GA-A10809, Gulf General Atomic Company, August 1971.

3. Wichner, R. P., and F. F. Dyer, 1979, "Distribution and Transport of Tritium in Peach Bottom HTGR," ORNL-5497.

4. Olson, H. G., and H. L. Brey, 1980, "The Fort Saint Vrain High Temperature Gas Cooled Reactor, VI Evaluation and Removal of Primary Coolant Contaminants," Nuclear Engineering and Design, Vol. 61, pp. 315-322.

5. Burnette, R., and N. Baldwin, 1980, "Primary Coolant Chemistry of the Peach Bottom and Fort St. Vrain High-Temperature Gas-Cooled Reactors," November 1980.

6. Sakaba, N., and H. Ohashi, 2006, "Hydrogen Permeation through Heat Transfer Pipes Made of Hastelloy XR during the Intial $950^{\circ} \mathrm{C}$ operation of the HTTR," Journal of Nuclear Materials, Vol. 353, pp. 42-51.

7. Saito, S., et al., 1994, Design of High Temperature Engineering Test Reactor (HTTR), Report of the Japan Atomic Energy Research Institute, JAERI 1332.

8. Yao, M. S., and R. P. Wang, 2002, "The Helium Purification System of the HTR-10," Nuclear Engineering and Design, Vol. 218, pp. 163-167.

9. Sun, Y., and Y. Xu, On the Issues of Fuel Storage and Decommissioning of the HTR-10 Test Reactor, Institute of Nuclear Energy Technology, Tsinghua University, Beijing.

10. Breuil, E., and D. Besson, 2004, Last Results from the HTR-E Project, High Temperature Components and Systems, $2^{\text {nd }}$ International Topical Meeting on High Temperature Reactor Technology, Beijing, China, September 22-24, 2004.

11. General Atomics, 1996, Gas Turbine-Modular Helium Reactor (GT-MHR) Conceptual Design Description Report, 910720, Revision 1, July 1996.

12. General Atomics, 1992, "Preliminary Safety Information Document for the Standard MHTGR," HTGR-86-024, September 9, 1992.

13. Kaufman, S., and W. F. Libby, 1973, Tritium Control Technology, WASH 1269, U.S. Atomic Energy Commission, Washington, D.C.

14. Sherman, S. R., and T. M. Adams, 2008, Tritium Barrier Materials and Separation Systems for the NGNP, SRNL-WSRC-STI-2008-00358, August 2008.

15. Chang, H., and W. Zong-Xin, 2009, "Experimental study on Adsorption of Carbon Dioxide by a $5 \mathrm{~A}$ Molecular Sieve for Helium Purification of High Temperature Gas Cooled Reactor," Industrial and Engineering Chemistry Research, Vol. 48, pp. 4466-4473.

16. Varias, A. G., 2004, “Simulation of hydride-Induced Steady-State Crack Growth in Metals - Part 1: Growth Near Hydrogen Chemical Equilibrium, Computational Mechanics," Vol. 34, pp. 339-356.

17. Wipf, H., and B. Kappesser, 2000, "Hydrogen Diffusion in Titanium and Zirconium Hydrides," Journal of Alloys and Compounds, Vol. 310, pp. 190-195.

18. Elder, R., Allen, R., Nuclear Heat Production - Coupling VHTR to Hydrogen Plant, Progress in Nuclear Energy 51, pp. 500-525, 2009. 
19. NGNP Materials White Paper, INL/EXT-09-17187, May 2010.

20. Effect of Reactor Outlet Helium Temperature on the Need for Composites in the NGNP, Report Number 911175, General Atomics, November 2009.

21. NGNP Technology Development Road Map Report, Document number TDR-3001031-002, AREVA, April 2009.

22. Test Plan - Steam Generator for 750 C Reactor Outlet Helium Temperature, General Atomics, document number 911174, GA, 2009.

23. Report on Update of Technology Development Roadmaps for NGNP Steam Production at 750 C-800 C, Westinghouse, Report number: NGNP-TDI-TDR-RPT-G-00003, May 2009.

24. Integration of High-Temperature Gas Cooled Reactors into Industrial Process Applications, INL/EXT-09-16942, Rev 1, February 2010.

25. Material Behavior in HTGR Environments, NUREG/CR-6824, U.S. Nuclear Regulatory Commission, 2003.

26. Rouillard, F., Cabet, C., High Temperature Corrosion of a Nickel Based Alloy by Helium Impurities, Journal of Nuclear Materials, 362, 248-252, 2007.

27. Cabet, C., Chapovaloff, J., High Temperature reactivity of two Chromium-Containing Alloys in Impure Helium, Journal of Nuclear Materials, 375, 173-184, 2008.

28. Xiaowei, L., and R. Jean-Charles, 2004, "Effect of Temperature on Graphite Oxidation Behavior," Nuclear Engineering Design, Vol. 227, pp. 273-280.

29. Raman, R., Gnanamoorthy, J., Oxidation of 2.25Cr-1 Mo Steel with Prior Tempering at Different Temperatures, Oxidation of Metals, 40, pp100-116, 1993.

30. The Next Generation Nuclear Plant Graphite Program, INL/CON-08-14693, September 2008.

31. Standard Specification for Isotropic and Near-isotropic Nuclear Graphites, D7219-08, 2008.

32. Graphite Technology Development Plan, INL/EXT-07-13165, September 2007.

33. Gainey, B. W., 1976, A Review of Tritium Behavior in HTGR Systems, GA-A13461, GA, April 1976.

34. Assessment of the Effects of Fort St. Vrain HTGR Primary Coolant on Alloy 800, Report Number NP-2548, August 1982.

35. Tunaboylu, K., and M. Paulovic, 1991, "Concept of a Tritium Extraction Facility for a Reprocessing Plant," Nuclear Engineering and Design, Vol. 130, pp. 71-76.

36. Fedorchenko, O. A., and I. A. Alekseev, 2001, "A New Type Separation Column for the Water Hydrogen Isotope Exchange Process," Fusion Engineering and Design, Vol. 58-59, pp. 433-438.

37. Alekseev, I. A., and S. D. Bondarenko, 2003, "Heavy Water Detritiation by Combined Electrolysis Catalytic Exchange at the Experimental Industrial Plant," Fusion Engineering and Design, Vol. 69, pp. 33-37.

38. Vasyanina, T. V., and I. A. Alekseev, 2008, "Heavy Water Purification from Tritium by CECE Process," Fusion Engineering and Design, Vol. 83, pp. 1451-1454.

39. Song, K. M., and S. H. Sohn, 2007, "Installation of Liquid Phase Catalytic Exchange Columns for the Wolsong Tritium Removal Facility," Fusion Engineering and Design, Vol. 82, pp. 2264-2268.

40. Sakaba, N., Furusawa, T., Short Design Descriptions of the other systems of the HTTR, Nuclear Engineering and Design 233, pp. 147-154, 2004. 
41. Wright, R., Kinetics of Gas Reactions and Environmental Degradation in NGNP Helium, INL/EXT06-11494, June 2006.

42. Brenner, K., Graham, L., Development and Application of a Unified Model for High-Temperature Gas-Cooled Reactor Systems, Nuclear Technology, Vol. 66, pp. 404-414.

43. Nieder, R. and Stroter, W., 1988, "Long-term Behavior of Impurities in an HTR Primary Circuit,"

44. VGB Kraftwerstechnik, Vol. 68, July 1988, pp. 671-676.

45. Nieder, R., "Prediction on an HTR Coolant Composition After Operational Experience with Experimental Reactors," Specialists Meeting on Coolant Chemistry, Plate-out and Decontamination in Gas Cooled Reactors, Juelich, FRG, December 1980, IAEA, Vienna, IWGGCR-2, pp. 144-152. 